\title{
EARLY ENDOTHELIAL PROGENITOR CELLS AS A SOURCE OF MYELOID CELLS TO IMPROVE THE PRE-VASCULARISATION OF BONE CONSTRUCTS
}

\author{
Yang Shi ${ }^{1}$, Gerhard Kramer ${ }^{2}$, Alexandra Schröder ${ }^{1}$, Charles James Kirkpatrick ${ }^{2}$, Andreas Seekamp ${ }^{1}$, Harald Schmidt ${ }^{3}$ \\ and Sabine Fuchs ${ }^{1}$
}

${ }^{1}$ Experimental Trauma Surgery, University Medical Centre Schleswig-Holstein, Kiel, Germany

${ }^{2}$ Institute of Pathology, Johannes Gutenberg University Mainz, Germany

${ }^{3}$ MetaPhysiol, Essenheim, Germany

\begin{abstract}
According to present knowledge, blood derived endothelial progenitor cells (EPC) might act as proangiogenic myeloid cells, which play a fundamental role in the regulation of angiogenesis and blood vessel reorganisation. In this context, we have evaluated the contribution of endogenous myeloid cells in co-cultures of blood derived outgrowth endothelial cells (OEC) and osteogenic cells. In addition, we investigated the role of EPC as a potential source of myeloid cells in the formation of vascular structures in an in vitro model consisting of mesenchymal stem cells (MSC) and OEC. For this purpose, we added EPCs to cocultures of MSC and OECs. Vascular structures and the co-localisation of myeloid cells were analysed by confocal laser microscopy (CLSM) for endothelial and myeloid markers and quantitative image analysis. The molecular effects of myeloid cells were evaluated by quantitative real time PCR, ELISA and protein arrays from cell culture supernatants and lysates. Endogenous myeloid cells were significantly co-localised with angiogenic structures in co-cultures of OEC and osteogenic cells. The active addition of EPC to co-cultures of OEC and MSC resulted in a statistically approved increase in the formation of prevascular structures at early stages of the co-culture process. In addition, we observed an increase of endothelial markers, indicating beneficial effects of EPC or myeloid cells on endothelial cell growth. Furthermore, real time PCR indicated high expression levels of CD68, CD11b and CD163 in co-cultures of EPC and MSC indicating that EPC act at least partly as macrophage like-cells.
\end{abstract}

Keywords: Vascularisation; myeloid cells; endothelial progenitor cells; bone regeneration; macrophages; interleukin-8; monocyte-chemoattractant protein-1.

*Address for correspondence:

Sabine Fuchs

Experimental Trauma Surgery

University Medical Centre Schleswig- Holstein

Kiel, Germany

Email: Sabine.Fuchs@uksh.de

\section{Introduction}

The formation of new blood vessels during tissue repair is an extremely complex process and involves many cell types and regulatory molecules. Endothelial cells are the major key players in the formation of new blood vessels during angiogenesis mediated by endothelial cell proliferation and vascular sprouting. Nevertheless, also mesenchymal cells acting as smooth muscle cells or pericytes (Au et al., 2008; Covas et al., 2008; Feng et al., 2011) play an important role in creating a functional and stable vasculature and stabilise newly formed vascular structures. These principles have entered the fields of regenerative medicine and biomedical engineering as reflected by the numerous studies in which co-culture approaches have been used to support the formation of functional vascular structures (Melero-Martin et al., 2007; Scherberich et al., 2007; Rouwkema et al., 2008; Laschke et al., 2012; Liu et al., 2012; Rivron et al., 2012). In addition, complex cell culture models have contributed to the understanding of blood vessel formation but still are far away from the scenario in vivo. Formation of new blood vessels depends on the interaction of endothelial cells with a series of other cells types such as myeloid cells, including bone marrow-derived macrophages or endothelial progenitor cells (Asahara et al., 1999; Yoder et $a l ., 2007)$. Increasing amounts of data from the literature provide evidence that myeloid cells and endothelial progenitor cells (EPC) share similar characteristics in their phenotype and pro-angiogenic functions in vivo (De Palma et al., 2007; Okuno et al., 2011; Van der Pouw Kraan et al., 2012). Nevertheless, the pro-angiogenic effect exerted by myeloid cells (Fantin et al., 2010) or EPC (Yoon et al., 2005) seems to be dependent on their interaction with mature endothelial cells by supporting vascular anastomosis. In this context, reports also pointed out the role of host myeloid cells recruited to sites of neovascularisation after co-implantation of endothelial cells and mesenchymal stem cells (Melero-Martin et $a l ., 2010)$. Thus, the active addition of myeloid cells could offer a new option for pro-angiogenic therapies. In our previous studies, we documented the potential of blood-derived outgrowth endothelial cells (OEC) to create functional blood vessels in co-culture or after coimplantation with osteogenic cells (Fuchs et al., 2010; Fuchs et al., 2009a; Ghanaati et al., 2011). OEC appear as mature endothelial cells in cultures of mononuclear cells from the peripheral blood. Besides OEC, mixed cell populations from the peripheral blood also contain cells named early EPC in accordance with their partly 
endothelial-like characteristics and their contribution to neovascularisation in vivo (Gulati et al., 2003; Hur et al., 2004). OEC and EPC as defined by Hur or Gulati et al. differ in their marker profile, as well as in their angiogenic potential in vitro as described elsewhere (Timmermans et al., 2009; Fuchs et al., 2010). In brief, OEC carry markers of mature endothelial cells such as CD31, VECadherin, caveolin-1, and von Willebrand factor, whereas EPC express for instance CD31 to a much lower extent. EPC in this context have to be considered as a highly heterogeneous population containing different cell types which actual role in the formation of angiogenic structures still needs to be defined.

In the present study, we investigated the role of CD11b-positive myeloid cells in the formation of angiogenic structures in various co-culture models. First, we investigated the contribution of endogenous myeloid cell populations in co-cultures of OEC and osteogenic cells by evaluating their co-localisation with angiogenic structures. Then, we actively added EPC in different ratios to co-cultures of OEC and MSC and analysed the effects on the formation of angiogenic structures in vitro by several methods.

\section{Materials and Methods}

\section{Isolation and expansion of human endothelial progenitor cells (EPCs) and outgrowth endothelial cells (OECs)}

Endothelial progenitor cells and outgrowth endothelial cells were isolated and cultured according to protocols as described previously (Fuchs et al., 2006a; Fuchs et al., 2006b; Fuchs et al., 2007). In brief, the mononuclear cells were isolated from peripheral blood buffy coats by Biocoll (Biochrom, Berlin, Germany) gradient centrifugation and cultured in endothelial cell growth medium-2 (EGM-2) (Lonza Walkersville, MD, USA) with full supplements from the kit, $5 \%$ foetal bovine serum (FBS) (PAA Laboratories, Pasching, Austria), and $1 \%$ penicillin/ streptomycin (Pen/Strep) (PAA Laboratories), on collagen (BD Biosciences, Bedford, MA, USA) coated 24-well culture plates. $5 \times 10^{6}$ mononuclear cells/well were seeded on 24-well culture plates and then fed with fresh medium every second day. The high seeding density was used due to the fact that not all cells adhered. After 1 week of culture, adherent cells were collected by trypsinisation and used as EPCs or reseeded in a density of $0.5 \times 10^{6}$ cells/well to collect OEC. Then, colonies of OECs with cobble-stonelike morphology, appearing after 2-3 weeks in culture, were trypsinised and expanded over several passages as described before.

\section{Isolation and expansion of mesenchymal stem cells (MSCs) and primary osteoblasts}

Human MSCs isolated from bone marrow of human cancellous bone fragments of adult donors were cultured and expanded as previously described (Kolbe et al., 2011). Bone fragments were washed several times with phosphate buffered saline (PBS; PAA Laboratories) to collect the loosely associated cell fractions. The washing solution containing bone marrow residues was filtered by cell strainer (BD Falcon, Franklin Lakes, NJ, USA) and centrifuged, and the cell pellet was resuspended in Dulbecco's Medium Essential Medium (DMEM)/Ham F-12 (Biochrom) supplemented with $20 \%$ FBS and $1 \%$ Pen/Strep. Cells were seeded at a density of $2 \times 10^{6}$ cells $/ \mathrm{cm}^{2}$ on collagen-coated flasks (T75). MSC-like colonies appearing after 7-10 days were expanded using a splitting ratio of 1:3 and were cultivated in DMEM/Ham F12 supplemented with $20 \%$ FBS and $1 \%$ Pen/Strep. Then MSC were cultivated in osteogenic differentiation medium (ODM) in passage two for 2 weeks to induce osteogenic differentiation before starting experiments. ODM consists of DMEM/Ham F-12 supplemented with $0.1 \mu \mathrm{M}$ dexamethasone (Sigma-Aldrich, St. Louis, MO, USA), $10 \mathrm{mM} \beta$-glycerol phosphate (Sigma-Aldrich), $50 \mu \mathrm{M}$ ascorbate-2-phosphate (Sigma-Aldrich), $10 \%$ FBS, and $1 \%$ Pen/Strep.

From the same bone fragments, primary osteoblasts were isolated by digestion of bone tissue with collagenase as previously described. In brief, bone fragments were minced and rinsed in PBS (phosphate buffered saline) for several times followed by the digestion of the bone tissue with collagenase (Type IV C-5138, Sigma-Aldrich) for one hour at $37{ }^{\circ} \mathrm{C}$. After the enzymatic digestion bone fragments were placed into 6-well culture plates and cultured in DMEM/Hams F12 (Gibco/Life Technologies, Carlsbad, CA, USA) including $20 \%$ FBS and $1 \%$ Pen/ Strep to allow the outgrowth of the cells from the bone fragments. Confluent cultures were passaged using acutase (PAA) in a ratio of 1:3 and further cultured in DMEM/ Hams F12 supplemented with $10 \%$ FBS.

\section{Flow cytometry}

For flow cytometry EPC from at least 3 different donors were harvested on day 7 as described above. Double labelling for CD31 as endothelial marker, in combination with several myeloid markers, was performed on unfixed cells using the following antibodies according to the manufactures recommendations: CD163-PE (Biolegend, San Diego, CA, USA), CD206-Alexa488 (R\&D Systems, Wiesbaden, Germany), CD68-PE (BD, Heidelberg, Germany), CD11b-APC (R\&D Systems), CD31-APC (Miltenyi, Bergisch Gladbach, Germany) CD31-FITC (Chemicon/Millipore, Billerica, MA, USA), as well as corresponding isotypic controls to adjust background fluorescence. Then samples were fixed using a fixation and permeabilisation kit from eBioscience (San Diego, CA, USA). Samples were analysed on a FACSCalibur (BD) analysing 10,000 cells and the results were quantified by quadrant statistics. For a more detailed facs analysis of EPC in terms of endothelial markers please refer to Fuchs et al. (2006a).

\section{Labelling of EPC with Cell Tracker Green}

To track the EPC in the co-cultures cells were labelled with cell tracker green at day 7 of the culture as described earlier (Fuchs et al., 2006a) and added to different groups for co-cultures as described in the following sections.

For co-cultivation to induce angiogenic structures by OEC we used the experimental set up described in earlier 
studies (Dohle et al., 2011; Kolbe et al., 2011). First MSC or primary osteoblasts were seeded at a density of 200,000 cells/ well in ODM on 24-well culture plates coated with fibronectin or on fibronectin-coated Thermanox coverslips (Nunc, Langenselbold, Germany) to allow evaluation of co-cultures by immnunofluorescence. After $24 \mathrm{~h}$ OEC were added at a density of 200,000 cells/ well. Co-cultures were further cultivated in EGM-2 for the indicated time points, which was chosen because this medium has shown the best effects on the formation of vascular structures.

Co-culture and triple culture of MSC, OEC and EPC To study the influence of EPC-derived myeloid cells on angiogenesis we used co-cultures based on (1) MSC and EPC, (2) MSC and OEC and (3) triple cultures of MSC and OEC to which we added $5 \%$ and $10 \%$ EPC per total cells. In a first step MSC were seeded onto the fibronectin (Millipore, Temecula, CA, USA) coated 24-well culture plates or on fibronectin-coated Thermanox coverslips at a density of 200,000 cells/well and cultivated in ODM. After 24 h, 200,000 OEC were added for co-cultures of $\mathrm{MSC} / \mathrm{OEC}$, and 200,000 OEC plus $5 \%$ or $10 \%$ of EPC for triple cultures. In addition $10 \% \mathrm{EPC}$ per well were added to MSC for the MSC/EPC set up. Co-culture and triple-culture were maintained in EGM-2 for 4 or 14 days.

\section{Immunofluorescence staining}

After 4 or 14 days co-cultures and triple-cultures seeded on Thermanox coverslips as described above were prepared for immunofluorescence staining. After fixation with $4 \%$ paraformaldehyde, cells were washed with PBS and permeabilised using $0.1 \%$ Triton ${ }^{\circledR}$ X-100 (Sigma-Aldrich, Taufkirchen, Germany). Cells were incubated with the following primary antibodies diluted in $1 \%$ bovine serum albumin (BSA) in PBS for $1 \mathrm{~h}$ at room temperature: CD31 (Dako, Glostrup, Denmark); CD31 (Santa Cruz, Dallas, TX, USA). CD11b (Epitomics, Burlingame, CA, USA); CD11b (Abcam, Cambridge, UK). After washing 3 times with phosphate-buffered saline (PBS), cells were incubated with the corresponding fluorescently labelled secondary antibodies (Invitrogen-Molecular Probes, Eugene, OR, USA) diluted 1:1000 in 1\% BSA in PBS for $1 \mathrm{~h}$ at room temperature. For nuclear counterstaining, cells were treated with 4',6-diamidino-2-phenylindole (DAPI). Samples were then observed using Zeiss (Oberkochen, Germany) LSM 510 Meta confocal laser scanning microscope.

\section{Image quantification and co-localisation studies}

Microscope images of immunofluorescence-stained cocultures and triple-cultures at different time points were analysed using ImageJ 1.43 (Rasband, 1997-2012) as introduced previously (Schmidt et al., 2012).

In brief, the tube-like structures were extracted from the immunofluorescent images stained for CD31 (Fuchs et al., 2009b) and analysed for the area, length, branching points and endpoints. According to these results, three regions of interest were established, the total area of tube-like structures and circular regions $(r=50 \mathrm{pixel})$ around the branching- and end-points. Finally, the immunofluorescent images stained for CD11b were analysed for co-localisation of positive cells by determination of the integrated density of CD11b fluorescence at the regions of interest. The relative intensity (relative intensity $=$ integrated density per area) for each region was calculated and the relative intensity of the whole image was used as a reference. The results of image analysis experiments are given as means \pm s.d., and significant differences between means were calculated with Microsoft-Excel. According to the results of a variance ratio analysis $(F$-test, $p<0.05)$ an unpaired $t$-test for either homoscedastic or heteroscedastic variances was performed $(* p<0.05$ and $* * p<0.01)$.

\section{Gene expression analysis}

To assess the expression of endothelial and myeloid markers, as well as the expression of angiogenic factors, semi-quantitative real-time polymerase chain reaction (RTPCR) was performed for CD146, von Willebrand factor (vWF), CD31 (Eurofins, www.eurofins.com), sm-actin,

Table 1. Primer assays used for real time PCR.

\begin{tabular}{|c|c|c|}
\hline Gene name & Primer assay name & Catalogue number \\
\hline vWF & Hs_VWF_1_SG QuantiTect Primer Assay & QT00051975 \\
\hline CD146 & Hs_MCAM_1_SG QuantiTect Primer Assay & QT00079842 \\
\hline sm-Actin & Hs_ACTA_1_SG QuantiTect Primer Assay & QT00088102 \\
\hline CD11b & Hs_ITGAM_1_SG QuantiTect Primer Assay & QT00031500 \\
\hline IL-8 & Hs_IL8_1_SG QuantiTect Primer Assay & QT00000322 \\
\hline CD68 & Hs_CD68_1_SG QuantiTect Primer Assay & QT00037184 \\
\hline CD163 & Hs_CD163_1_SG QuantiTect Primer Assay & QT00074641 \\
\hline CD206 & Hs_MRC1_1_SG QuantiTect Primer Assay & QT00012810 \\
\hline Integrin $\alpha 5$ & Hs_ITGA5_1_SG QuantiTect Primer Assay & QT00080871 \\
\hline GAPDH & Hs_GAPDH_1_SG QuantiTect Primer Assay & QT00079247 \\
\hline Gene name & Sequence & Annealing temperature \\
\hline CD 31 & $\begin{array}{c}\text { for 5'-CCGGATCTATGACTCAGGGACCAT-3' } \\
\text { rev 5'-GGATGGCCTCTTTCTTGTCCAG-3' }\end{array}$ & \\
\hline VEGF & for 5'-AAATGTGACAAGCCAAGGCGG-3' & \\
& rev 5'-AAAGTGCTCCTCGAAGAGTCTCC-3' & \\
\hline
\end{tabular}


CD11b, IL-8, vascular endothelial growth factor (VEGF) (Eurofins), and Glycerin-Aldehyde-3-phosphate (GAPDH) as internal control. If not stated otherwise primers were ordered from Qiagen (Qiagen, Hilden, Germany). For detailed information of used primers please refer to Table 1 . For gene expression analysis, total RNA was extracted from different culture set-ups using RNeasy Kit (Qiagen, Hilden, Germany) according to the manufacturer's protocol. A total amount of $1 \mu \mathrm{g}$ RNA was transcribed into cDNA using High capacity RNA-to cDNA Kit (Applied Biosystems, Carlsbad, CA, USA). Quantitative real-time PCR was performed using iCycler iQ Real-Time Detection System (Bio-Rad, Hercules, CA, USA). $12.5 \mu \mathrm{L}$ of QuantiTect ${ }^{\mathrm{TM}}$ SYBR $^{\circledR}$ Green PCR Master Mix (Qiagen), $2.5 \mu \mathrm{L}$ of QuantiTect ${ }^{\mathrm{TM}} \mathrm{SYBR}^{\circledR}$ Green primer assay (Qiagen), $6 \mu \mathrm{L}$ of RNase free water (Qiagen), and $4 \mu \mathrm{L}$ of cDNA were used for one reaction. For amplification, the following thermocycler program was performed. 1 cycle: 2 min at $50{ }^{\circ} \mathrm{C} ; 1$ cycle: $8 \mathrm{~min}$ at $95^{\circ} \mathrm{C} ; 40$ cycles: $30 \mathrm{~s}$ at $95^{\circ} \mathrm{C}, 30 \mathrm{~s}$ at $55^{\circ} \mathrm{C}, 30 \mathrm{~s}$ at $72{ }^{\circ} \mathrm{C} ; 80$ cycles: $30 \mathrm{~s}$ at $55^{\circ} \mathrm{C} ; 1$ cycle: hold at $20^{\circ} \mathrm{C}$. GAPDH was used as internal control and relative gene expression was determined using the $\Delta \Delta \mathrm{Ct}$ method. Gene expression was compared setting control cultures to 1 (reference value) as indicated in the relevant figures.

\section{Quantification of different growth factors using enzyme-linked immunosorbent assay (ELISA)}

The concentration of different growth factors in cell culture supernatants from different culture set ups of MSC, OEC and EPC in EGM-2 collected after 4 and 14 days were measured using ELISA DuoSet ${ }^{\circledR}$ for IL-8 and VEGF (R\&D Systems, Wiesbaden, Germany). In addition, ELISA for MCP-1 was performed using cell culture supernatants after 4 days of culture and the ELISA DuoSet from R\&D Systems, Wiesbaden, Germany. All ELISAs were performed according to the manufacturer's instructions. A streptavidin-HRP (horseradish-peroxidase) colorimetric reaction was used to determine protein concentrations. The optical density of each well was measured using an automatic plate reader (Apollo, Berthold Technologies, Bad Wildbad, Germany) capable of measuring absorbance at $450 \mathrm{~nm}$. After background subtraction concentrations were determined according to a standard calibration curve. In co-cultures and triple cultures ELISA data were normalised to the DNA content of each sample to compensate for the different cell numbers in the set up. The DNA content of co-cultures and triple cultures was determined by Quant-iT Pico Green dsDNAAssay Kit (Invitrogen) according to the manufacturer's protocol and analysed with a fluorescence microplate reader (Tecan, Crailsheim, Germany) at an excitation/emission wavelength of 485/535 nm.

\section{Protein arrays for angiogenesis- and haematopoiesis- related proteins}

In a first step MSC were seeded onto the fibronectin (Millipore, Temecula, CA, USA) coated 6-culture well plates at a density of $2.14 \times 10^{5}$ cells $/ \mathrm{cm}^{2}$ for MSC monocultures and $1.07 \times 10^{5}$ cells $/ \mathrm{cm}^{2}$ for $\mathrm{MSC} / \mathrm{OEC}$ co-cultures and triple-cultures (OEC/MSC/10 \% EPC) and cultivated in ODM. After $24 \mathrm{~h}, \mathrm{OEC}$ in a density of $1.07 \times 10^{5}$ cells $/ \mathrm{cm}^{2}$ were added for MSC/OEC cocultures and for triple-cultures (OEC/MSC/10 \% EPC). $10 \%$ per total cells of EPC were added to triple cultures. After 4 days, cells were lysed in buffers according to the recommendations for the protein arrays. In addition, proteins were harvested from the corresponding cell culture supernatants after centrifugation. The total protein concentration in individual samples was determined by the Bradford assay and measured at $562 \mathrm{~nm}$ using an automatic plate reader (Apollo, Berthold Technologies, Bad Wildbad, Germany). Protein-extracts derived from 3 different donors were subsequently pooled group wise at equal ratios to assess an average protein profile for each sample group. Proteome Profiler ${ }^{\mathrm{TM}}$ Human Angiogenesis Array and Proteome Profiler ${ }^{\mathrm{TM}}$ Human Haematopoietic Array were performed according to the manufacturer's protocol. Proteins were detected by chemiluminescence and analysed quantitatively using FUSION imaging system (PEQLAB, Erlangen, Germany) equipped with fusion software (Vilber Lourmat, Torcy, France).

\section{Statistical analyses}

Data are presented as mean values \pm standard deviation of the mean. Statistical significance was assessed using the unpaired students $t$-test and one-way ANOVA ( $p$-value $* p<0.05$ and $* * p<0.01)$ as indicated in the individual experiments. Statistical analysis was performed with Excel and GraphPad (LaJolla, CA, USA) Prism. Statistical significance was demonstrated when the $p$-values were less than 0.05 .

\section{Results}

Co-localisation of endogenous CD11b-positive cells in co-cultures of $\mathrm{OEC}$ and osteogenic cells

Immunofluorescent labelling of CD11b-positive cells was performed in co-cultures of OEC with MSC (Fig. 1A) or pOB (data not shown), respectively, at different time points of the co-culture process and analysed by confocal laser scanning microscopy (CLSM). In addition, vascular structures which have been visualised by staining for the endothelial marker CD31 were quantified and the co-localisation of CD11b-positive cells was evaluated by assessing a correlation of CD11b-positive cells with the area, the nodes or the ends of vascular structures as depicted in Fig. 1B and Fig. 1C. An example of what was considered as an angiogenic structure for the quantification process is depicted in Fig. 1B. In co-cultures of OEC with MSC we found a significant co-localisation of CD11b-positive cells with the area of vascular structures at day 21 (Fig. 1B) for all tested donors. For the co-culture of OEC with pOB we observed the same trend but the data could not be approved in a statistical consistent manner due to low sample size (data not shown) $(n<3)$.

\section{Characterisation of endothelial progenitor cells for myeloid markers}

Detailed characterisation of EPC in terms of their endothelial characteristics has been reported elsewhere (Fuchs et al., 2006a). Here we investigated EPC as a 

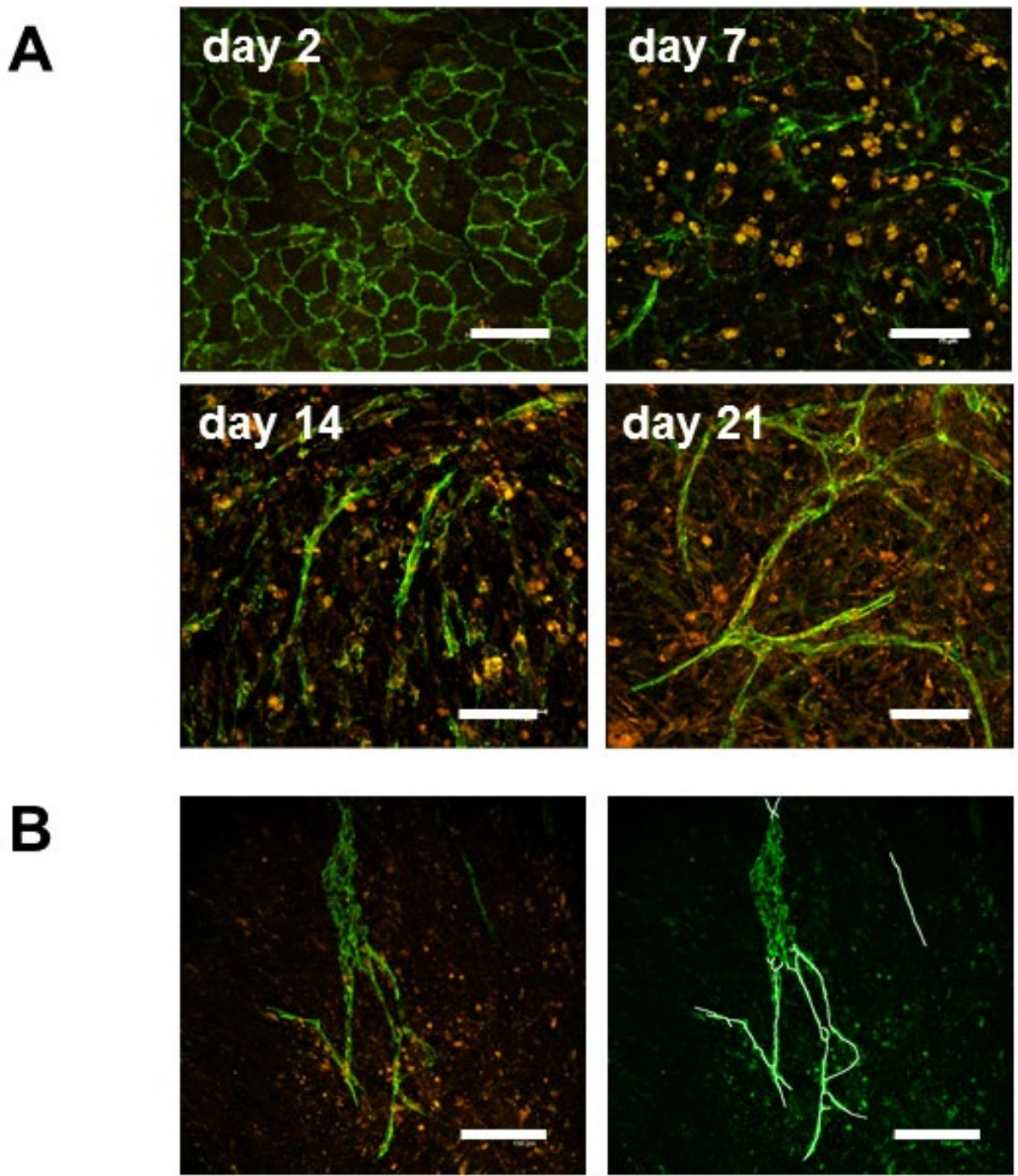

C
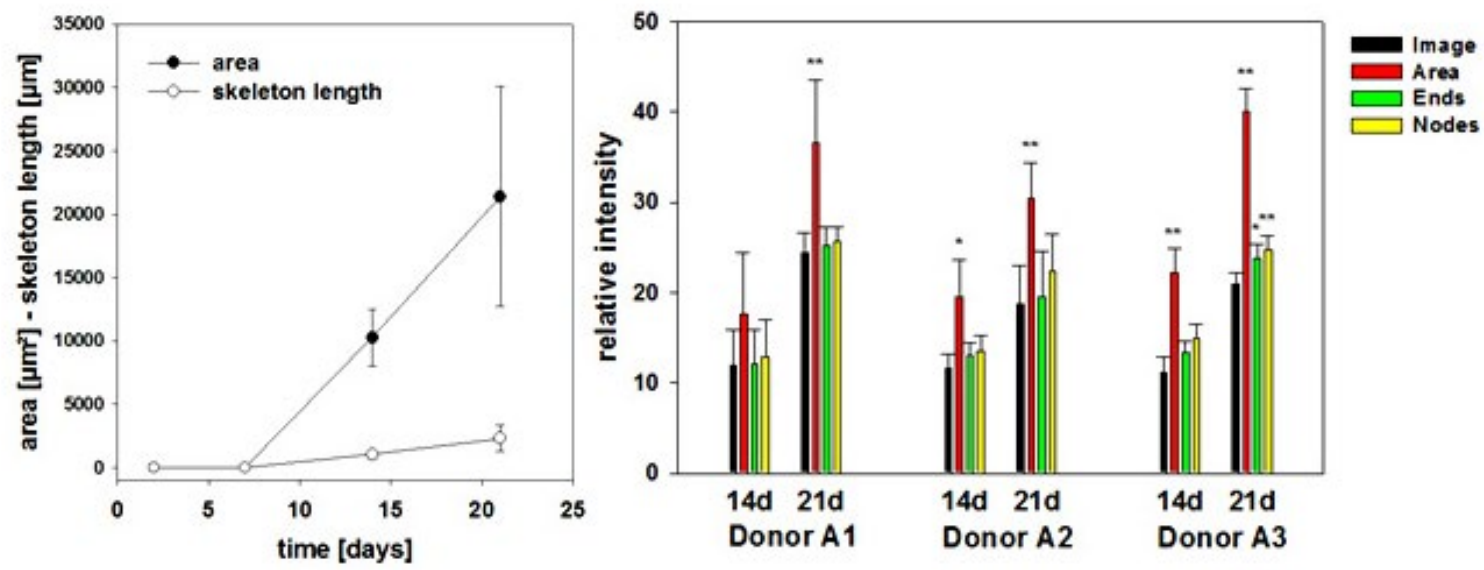

Fig. 1. Co-localisation of myeloid cells with angiogenic structures in co-cultures of OEC with mesenchymal stem cells. (A) Co-cultures and angiogenic structures at different time points. Co-cultures are stained for CD31 (green) and CD11b (red). Scale bar $75 \mu \mathrm{m}$. (B) Example of angiogenic structure used for the quantification process. The skeleton of the vascular structure is depicted as white lines. Scale bar $150 \mu \mathrm{m}$. Samples were stained according to the description in (A). (C) Quantification of angiogenic structures over time (left graph) and evaluation of co-localisation of CD11b with vascular structures (right graph) in co-cultures of OEC and MSC. The relative intensity of CD11b stained images was determined for the whole image (image), the angiogenic area (area) and circular regions around the endpoints (ends) and branching points (nodes). Evaluation is depicted for three independent experiments (Donor A1, A2, A3, $n=3$ or 4 samples). The relative intensity of the whole image was used as reference for the calculation of significant differences $(* p<0.05, * * p<0.01 ; t$-test $)$. 
Table 2. Summary of flow cytometric evaluation of endothelial progenitor cells in terms of CD31 and myeloid markers depicted in \% of positive cells and the standard variation in the individual regions.

\begin{tabular}{|c|c|c|}
\hline & Small cells & Large cells \\
\hline Ratio in \% & $74.9[ \pm 14.1]$ & $7.23[ \pm 3.3]$ \\
\hline \multicolumn{3}{|c|}{ Marker in \% of cells in the individual region } \\
\hline CD163 & $0.1 \%[ \pm 0.1]$ & $0.8 \%[ \pm 1.2]$ \\
\hline CD31/CD163 & $0.0 \%[ \pm 0.1]$ & $0.9 \%[ \pm 1.4]$ \\
\hline CD11b & $1.7 \%[ \pm 1.2]$ & $61.5 \%[ \pm 22.5]$ \\
\hline CD11b/CD31 & $0.6 \%[ \pm 0.5]$ & $12.8 \%[ \pm 8.3]$ \\
\hline CD206 & $0.3 \%[ \pm 0.2]$ & $66.0 \%[ \pm 26.6]$ \\
\hline CD206/CD31 & $0.3 \%[ \pm 0.2]$ & $65.7 \%[ \pm 26.0]$ \\
\hline CD68 & $6.0 \%[ \pm 7.3]$ & $83.3 \%[ \pm 12.3]$ \\
\hline CD68/CD31 & $6.1 \%[ \pm 7.2]$ & $84.2 \%[ \pm 11.4]$ \\
\hline CD146 & $2.57 \%[ \pm 1.77]$ & $1.5 \%[ \pm 1.66]$ \\
\hline
\end{tabular}

( $n=3$ different donors).

$\mathrm{MSC}+10 \% \mathrm{EPC}$

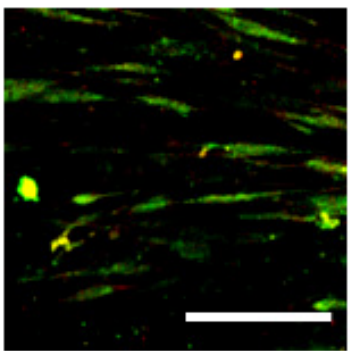

A
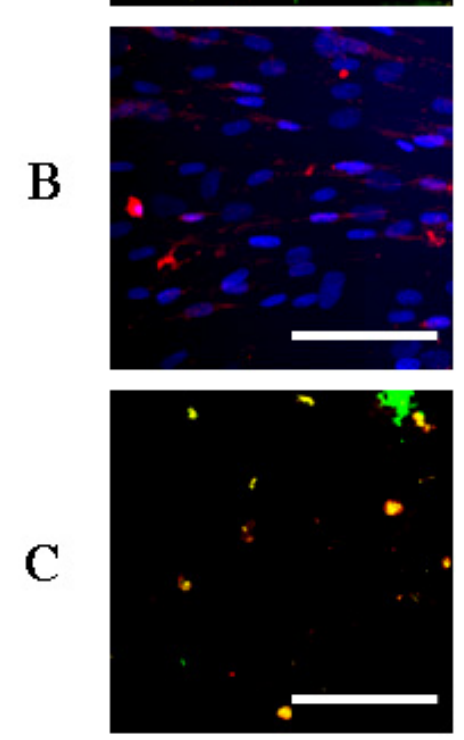

\section{B}

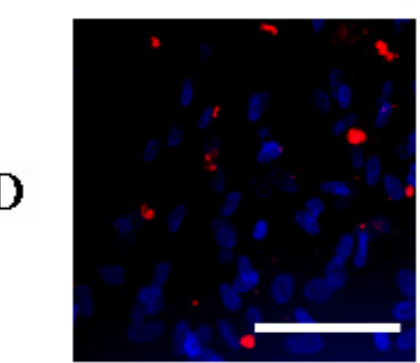

$\mathrm{MSC}+\mathrm{OEC}$
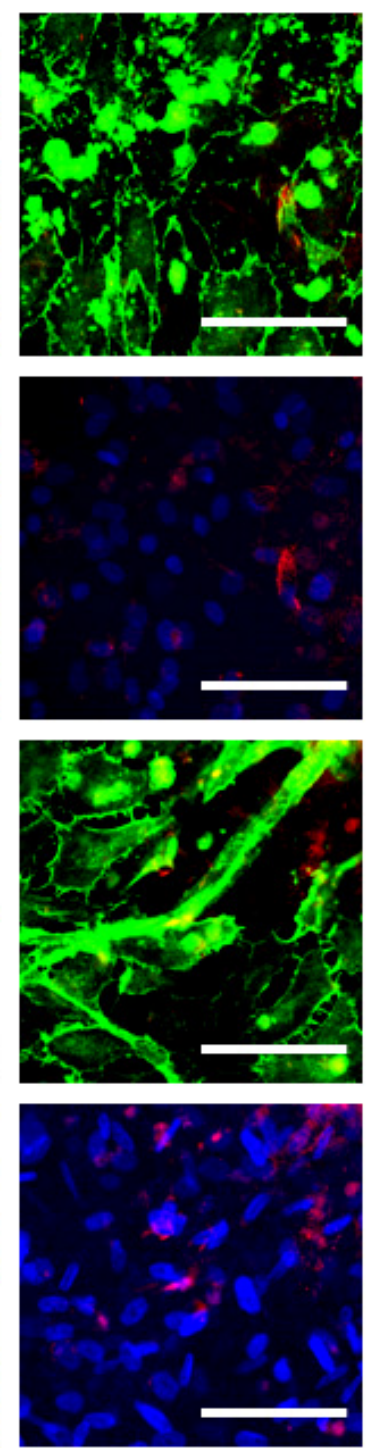

potential source of myeloid cells by double staining for CD31 in combination with several markers described for myeloid cells or macrophages on the single level by flow cytometry. In flow cytometry two main populations were identified which were named in accordance with the scatter profile as small and as large populations. Accordingly, those cells were gated and analysed separately. The results analysed from 3 donors of EPC are depicted in Table 2 for small and large cells in percentage of total. Large cells in EPC cultures were characterised by a series of myeloid markers or macrophage associated markers such as CD11b, CD206 and CD68. In double labelling experiments relatively high proportions of double positive cells for CD31/CD68 and CD31/CD206 were also observed in myeloid cells contained within the populations of the larger cells. In smaller cells, those markers were found to a much lower extent. In order to support these results we also performed real time PCR for these markers that allowed us to gain insight in to the average expression of the markers
$\mathrm{MSC}+\mathrm{OEC}+5 \% \mathrm{EPC} \quad \mathrm{MSC}+\mathrm{OEC}+10 \% \mathrm{EPC}$
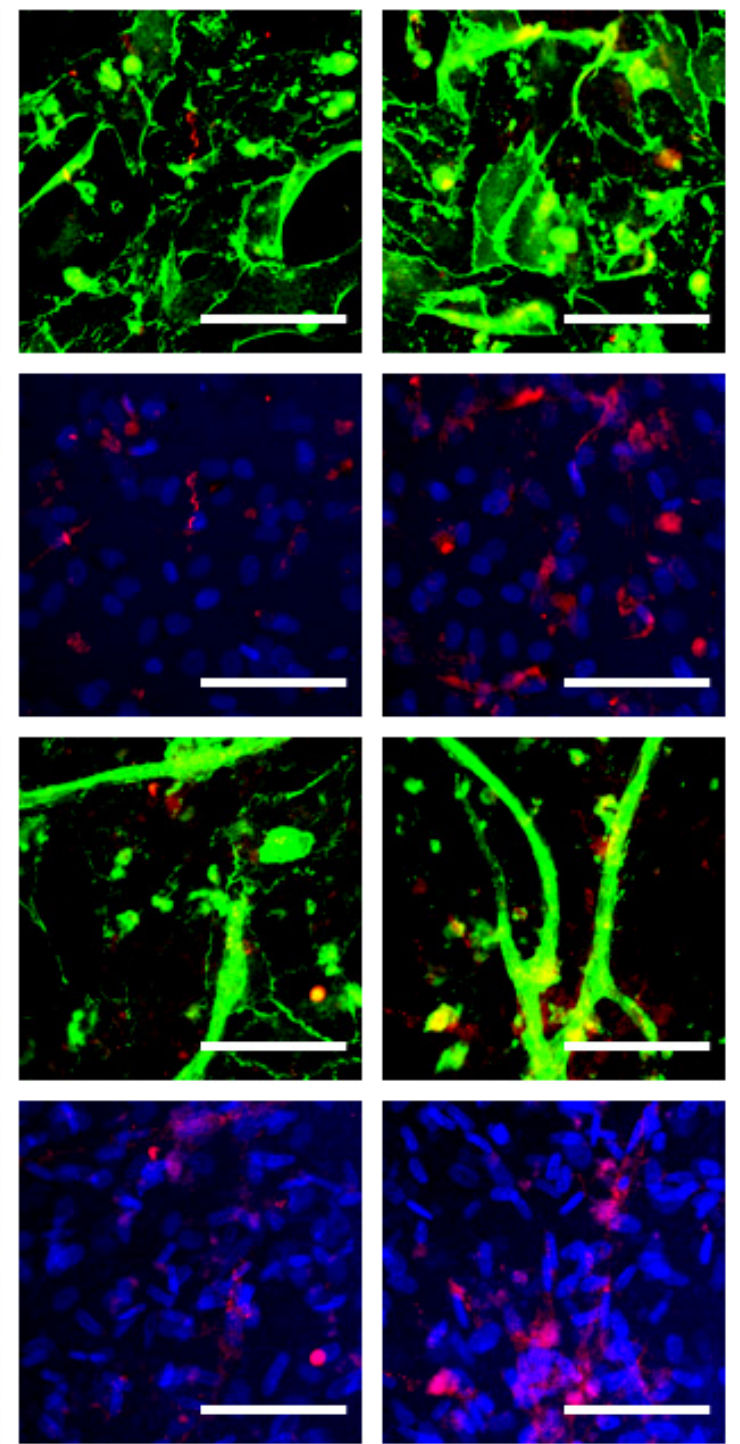

Fig. 2. Immunofluorescent staining of co-cultures (MSC $+10 \% \mathrm{EPC}, \mathrm{MSC}+\mathrm{OEC}$ ) or triple-cultures (MSC $+\mathrm{OEC}+5 \% \mathrm{EPC}$ or $\mathrm{MSC}+\mathrm{OEC}+10 \% \mathrm{EPC}$ ). Co-cultures and triple-cultures as indicated in the individual columns were analysed for the endothelial marker $\mathrm{CD} 31$ depicted in green $(\mathbf{A}, \mathbf{C})$ and myeloid marker $\mathrm{CD} 11 \mathrm{~b}$ depicted in red $(\mathbf{A}, \mathbf{B}, \mathbf{C}, \mathbf{D})$ after 4 days (A, B) and 14 days (C, D). nuclei (blue), bar $=100 \mu \mathrm{m}$. 

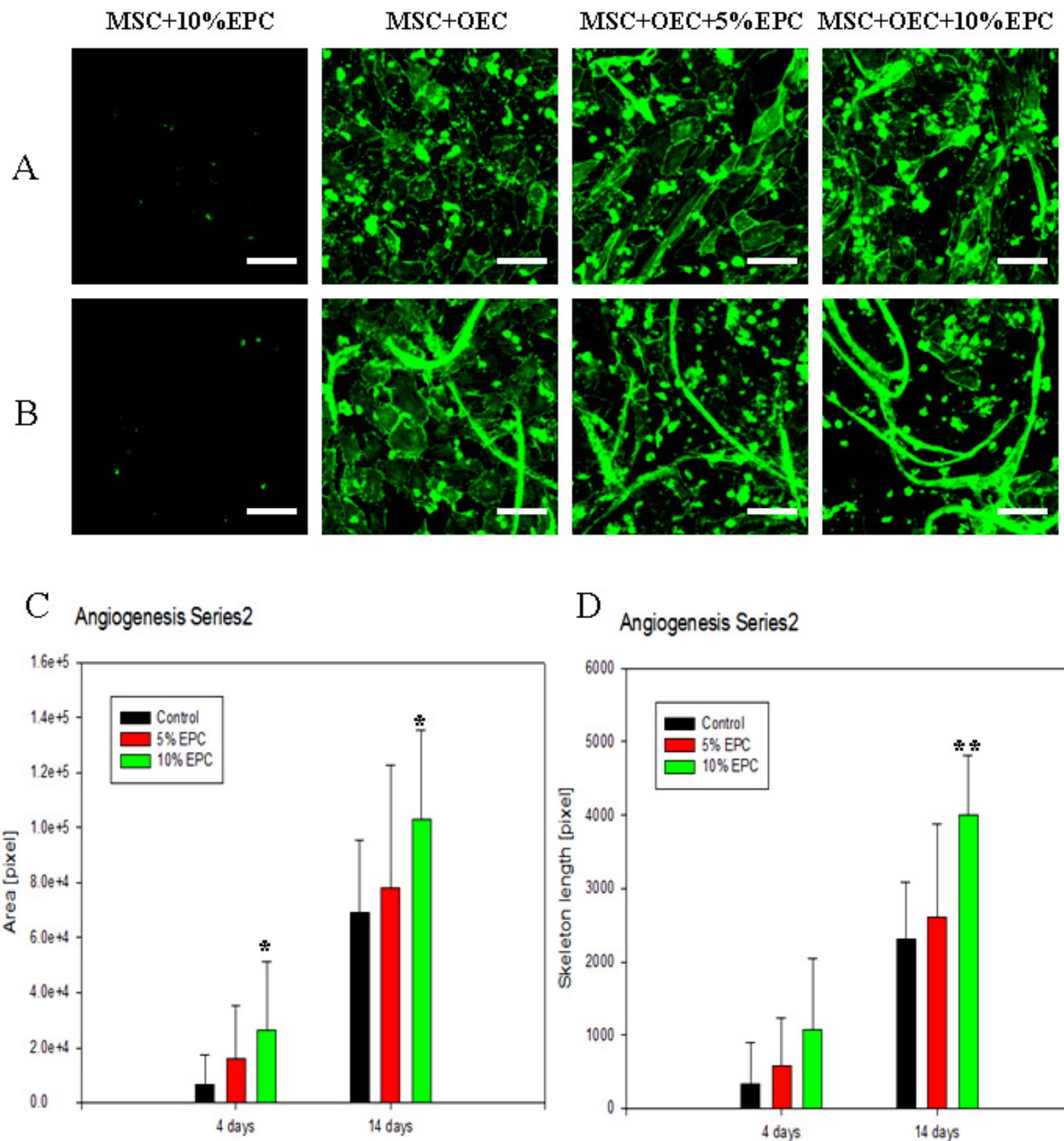

\section{Angiogenesis Series2}

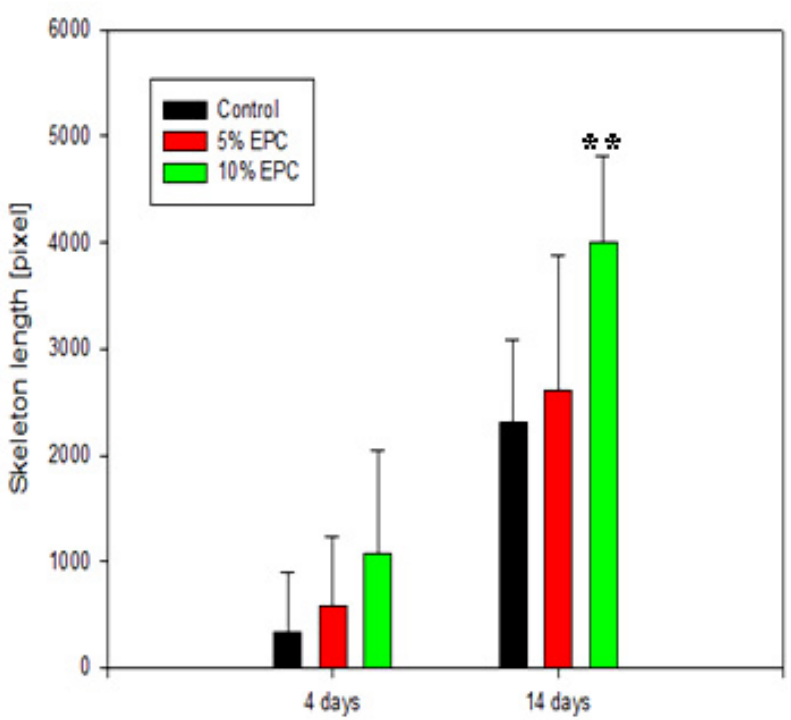

Fig. 3. Quantitative assessment of vascular structures influenced by the addition of EPC. Co-cultures (MSC, OEC and $\mathrm{MSC}, \mathrm{EPC})$ and triple-cultures $(\mathrm{MSC}+\mathrm{OEC}+5 \% \mathrm{EPC}, \mathrm{MSC}+\mathrm{OEC}+10 \% \mathrm{EPC})$ were stained for the endothelial marker CD31 after 4 days $(\mathbf{A})$ and 14 days $(\mathbf{B})$. The area $(\mathbf{C})$ and the total skeleton length $(\mathbf{D})$ of vascular structures formed by co-cultures and triple-cultures after 4 days and 14 days were assessed quantitatively. Statistical significance was defined as a $p$-value of less than $0.05\left({ }^{*} p<0.05\right.$ and ${ }^{*} p<0.01 ; t$-test $) n=9$ samples. Bar: $100 \mu \mathrm{m}$.

in the whole cell population (data not shown). In these experiments, we also used OEC and MSC, which revealed low expression rates for myeloid markers. These results further confirmed EPC as the main source of myeloid cells revealing a very high expression of CD11b, CD68, CD206 when compared to OEC or MSC, respectively. In contrast to the flow cytometry data, CD163 was also detected in EPC by real time PCR.

Effects of myeloid cells on angiogenic structures determined by confocal microscopy and quantitative picture analysis

To further define the role of the CD11b-positive or myeloid cells during angiogenesis and to see whether EPC, as a source of CD11b-positive or myeloid cells, actively contribute to the formation of vascular structures, we added early EPC to the co-culture system of OEC and MSC and evaluated angiogenesis.

The formation of angiogenic structures and the associated myeloid cells after 4 (Fig. 2A, B) and 14 days (Fig. 2C, D) were investigated by immunofluorescent staining for endothelial markers such as CD31 (A, C; in green). In addition, CD11b (depicted in red, Fig. 2A-D) was used as a marker for myeloid cells. During the time course of the co-cultures, OEC formed angiogenic structures characterised by elongated endothelial morphology. The addition of early EPC to the co-cultures of MSC and OEC seemed to increase the number of vascular structures 


\section{Day-4}

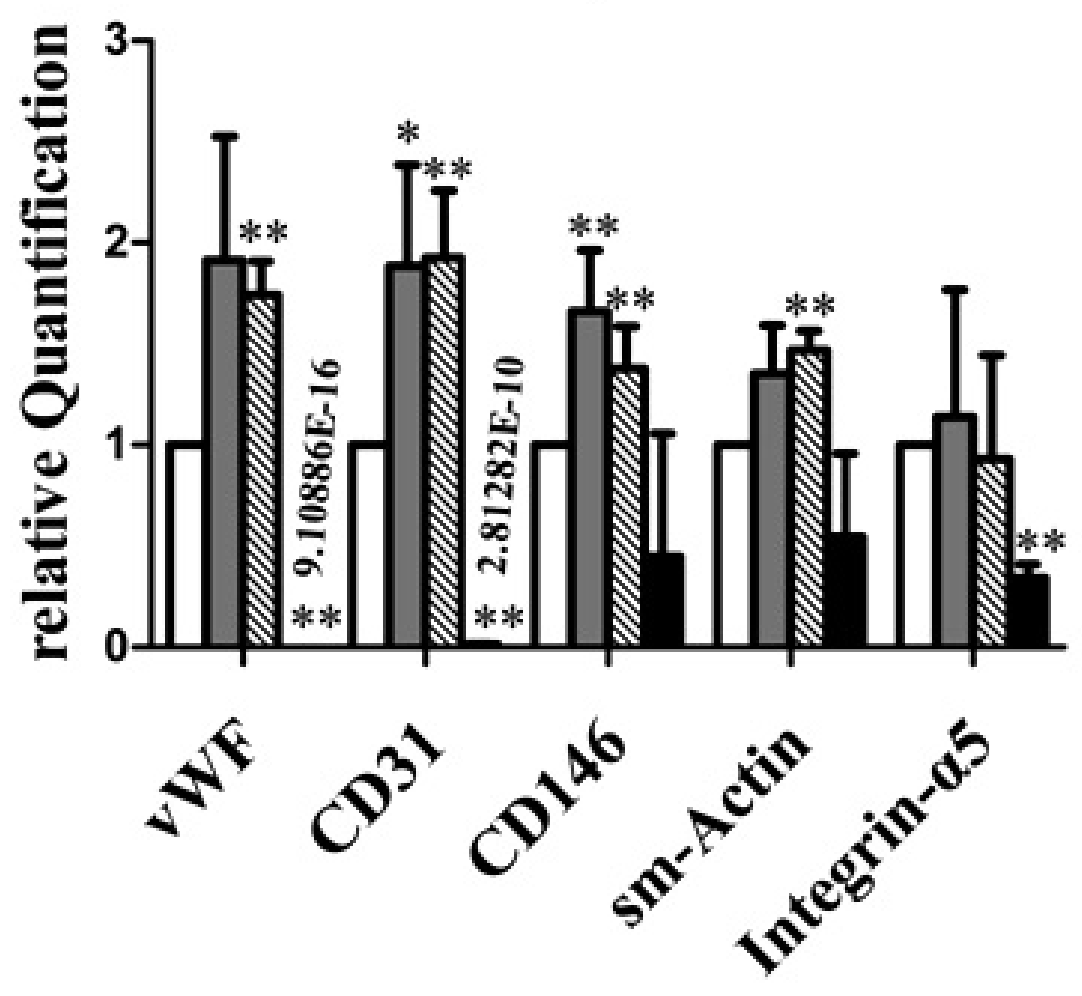

Day-14

Fig. 4A. Expression of endothelial and myeloid markers. Relative expression of endothelial or angiogenesis-related markers in co-cultures and triple-cultures was investigated by quantitative realtime PCR after 4 days and 14 days. GAPDH was used as an endogenous standard to normalise the data and control co-cultures were set to 1 $\left({ }^{*} p<0.05\right.$ and $* * p<0.01, t$-test $)$ $n=3$.

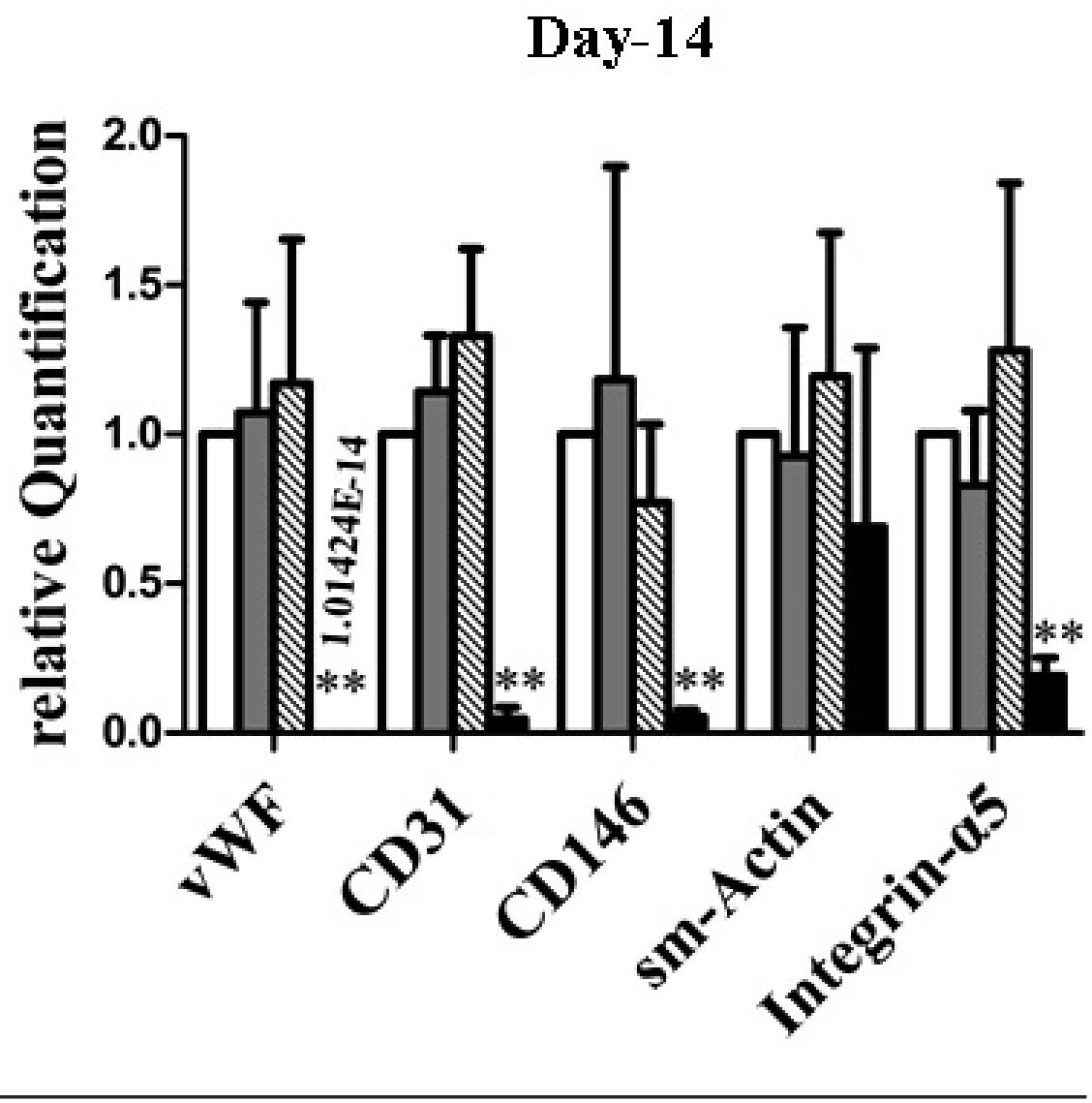

present in the co-cultures, whereas in additional controls of MSC/EPC co-cultures no vascular structures were detected at the investigated time points. Myeloid cells were characterised by a more rounded morphology and $\mathrm{CD} 11 \mathrm{~b}$ expression depicted in red. In addition, rounded CD11b-positive cells partly expressed also the endothelial marker CD31. CD11b-positive myeloid cells were closely associated with the angiogenic structures, indicating an active role in the formation of vascular structures to be further defined. A potential integration of myeloid cells into vascular structures might occur but could not be proven at the present stage of investigation. Cell tracking 
Day-4

CD11b

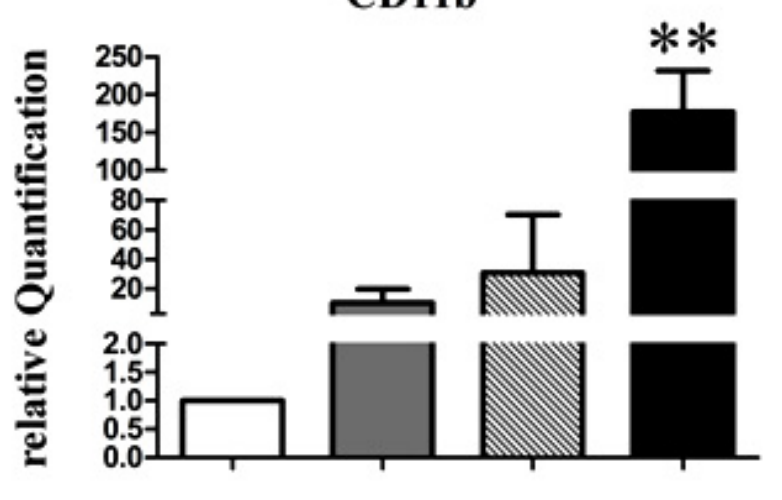

CD163

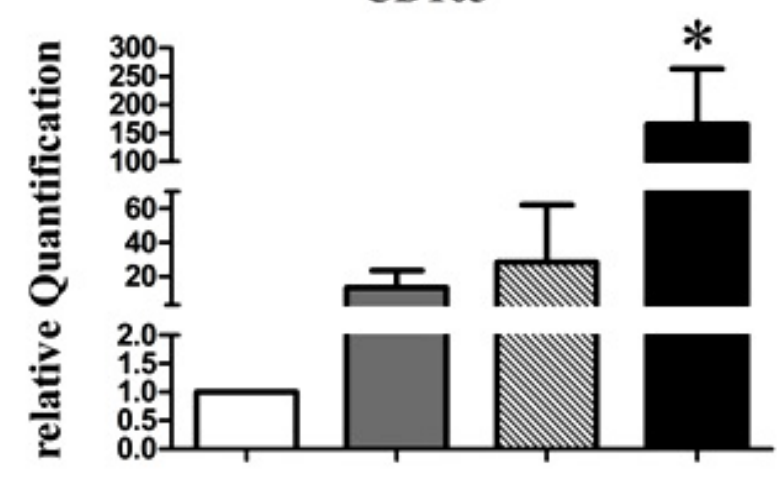

CD68

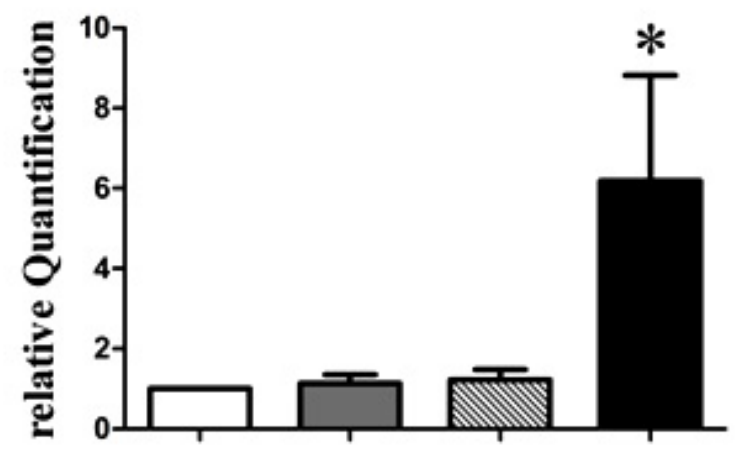

$\square \mathrm{MSC}+\mathrm{OEC}$

a $\mathrm{MSC}+\mathrm{OEC}+10 \% \mathrm{EPC}$
Day-14

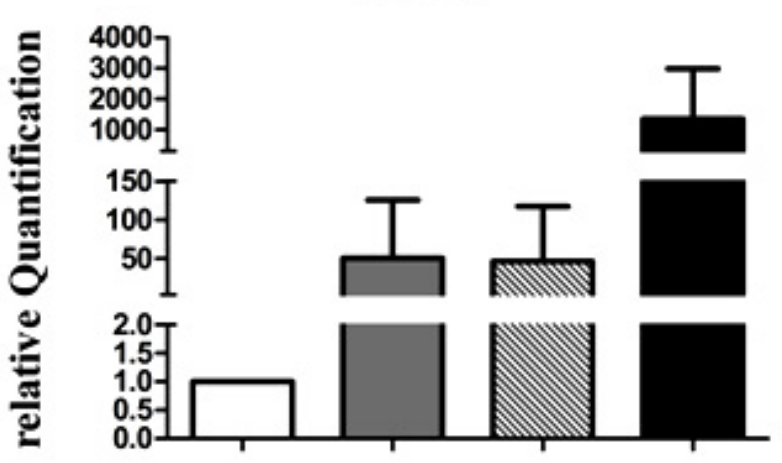

\section{CD163}

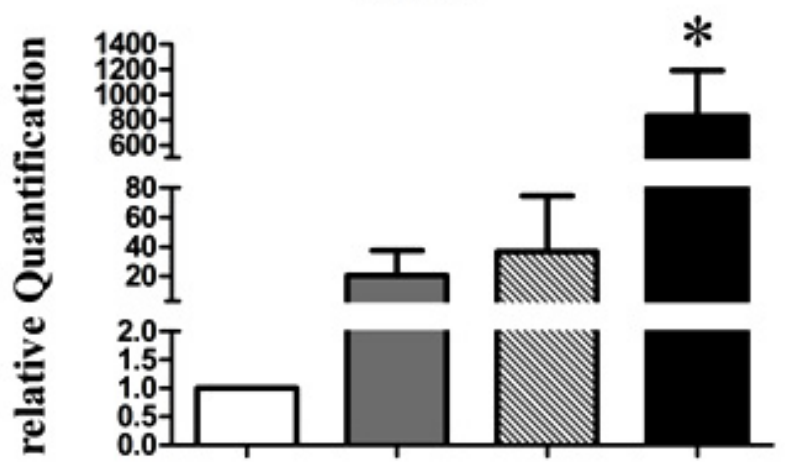

CD68

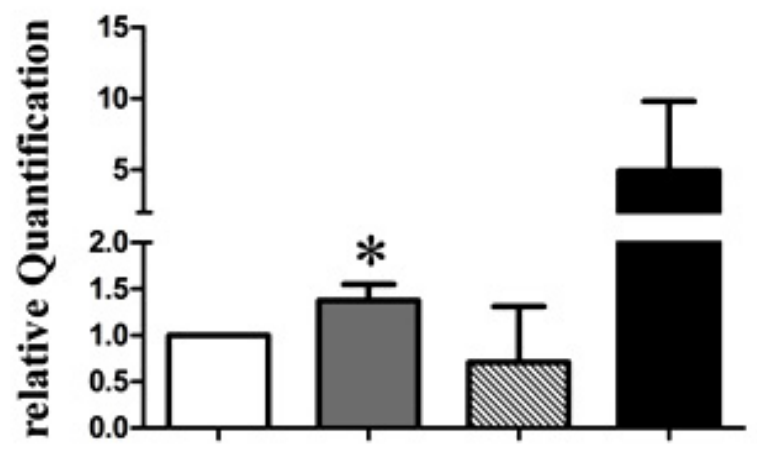

$\mathrm{MSC}+\mathrm{OEC}+5 \% \mathrm{EPC}$

$\mathrm{MSC}+10 \% \mathrm{EPC}$

Fig. 4B. Expression of endothelial and myeloid markers. Myeloid or macrophage-associated markers (B) in co-cultures and triple-cultures was investigated by quantitative real-time PCR after 4 days and 14 days. GAPDH was used as an endogenous standard to normalise the data and control co-cultures were set to $1\left({ }^{*} p<0.05\right.$ and $* * p<0.01, t$-test $) n=3$.

experiments (data not shown) indicated the association cell tracker green-labelled endothelial progenitor cells of EPC with angiogenic structures at the tip or around vascular structures, as well as expression of CD31 in rounded EPC but no real integration into endothelial tubes or interconnected cell layers. Similar patterns were observed before in the co-stainings for endothelial and myeloid markers suggesting that EPC act as accessory cells in the formation of vascular structures.

The effect of the addition of EPC on angiogenesis was quantified by image analysis in cultures from at least three different donors as depicted in Fig. 3. Representative 
A

IL-8

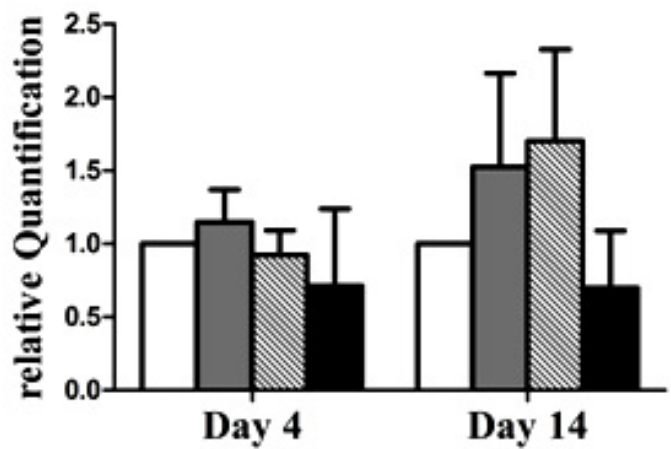

C

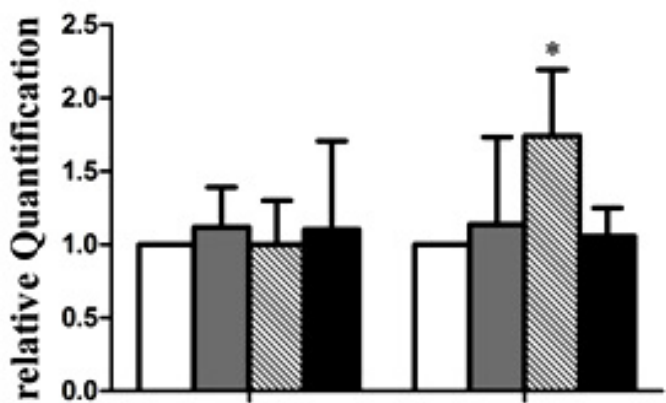

Day 4

Day 14
B

IL-8

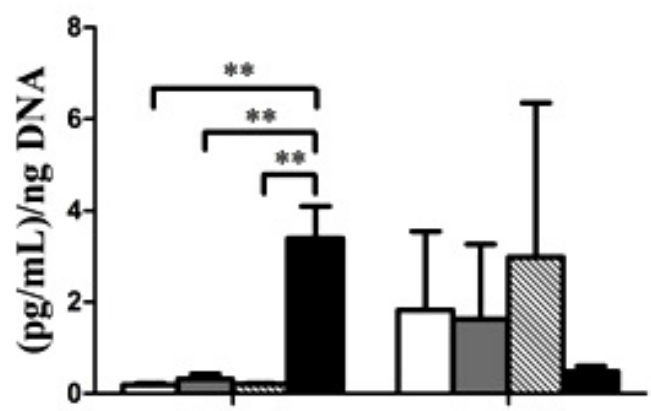

Day 4

Day 14

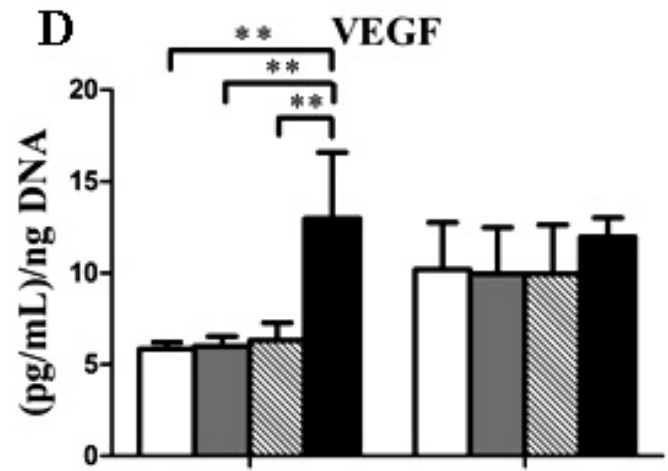

Day 4

Day 14

\section{$\square \mathrm{MSC}+0 \mathrm{EC} \square \mathrm{MSC}+0 \mathrm{EC}+5 \% \mathrm{EPC} \quad \mathbb{M} \mathrm{MSC}+0 \mathrm{EC}+10 \% \mathrm{EPC} \square \mathrm{MSC}+10 \% \mathrm{EPC}$}

Fig. 5. Relative quantification of gene expression of the proangiogenic factors IL-8 (A) and VEGF (C) in co-cultures and triple-cultures after 4 days and 14 days. GAPDH was used as an endogenous standard to normalise the data and control co-cultures were set to $1\left({ }^{*} p<0.05\right.$ and $* * p<0.01, t$-test) $n=3$. (B, D) Release of proangiogenic factors in co-cultures and triple-cultures. The concentration of IL-8 (B) and VEGF (D) in the supernatants of co-cultures and triple-cultures after 4 days and 14 days was measured using an enzyme-linked-immunosorbent-assay. Results were normalised to the DNA content of each sample to compensate for the different cell numbers in the set up. Statistical analysis was performed using ANOVA $(* p<0.05$ and $* * p<0.01) n=3$.

overview pictures underlying the quantification process are depicted for day 4 (Fig. 3A) and for day 14 (Fig. 3B). In comparison to the control group, represented by the coculture of MSC and OEC, EPC added in a ratio of $10 \%$ per total cells to the co-culture resulted in a significant increase in the area of vascular structures at both investigated time points and with regard to the skeleton of the vascular structures after 14 days of the culture process.

\section{Effects of myeloid cells on endothelial, myeloid and vessel-stabilising markers and genes}

To assess the effects exerted by myeloid cells added to the culture system in more detail, we further evaluated endothelial markers such as vWF, CD31, CD146, as well as smooth muscle actin involved in vascular stabilisation and integrin- $\alpha 5$ by quantitative real time PCR (Fig. 4A). Compared to the co-cultures of OEC and MSC used as reference group, the expression of endothelial markers at day 4 was significantly higher in OEC/MSC co-cultures when EPC were added (Fig. 4A), although the effects comparing $5 \%$ and $10 \%$ of EPC were not consistent. The same trend was observed for smooth muscle actin associated with the vascular stabilisation by pericytes and integrin $\alpha-5$ associated with angiogenic activation of endothelial cells.

In addition, real time PCR was performed to analyse myeloid or macrophage-related markers expressed by EPC or macrophage-like cells in the co-cultures. In these real time PCR experiments the highest expression of CD11b as a marker of myeloid cells was observed in the MSC/10\% EPC co-cultures compared to the other groups, which further confirms that EPC are the main source of myeloid cells in our co-culture scenarios (Fig. 4B). Similar findings were observed for CD68 and CD163 used as macrophage markers for which we found significantly higher expression rates in MSC/EPC co-cultures than in the OEC/MSC cocultures.

\section{Expression and secretion of IL-8 and VEGF}

To assess the mechanisms responsible for the positive angiogenic effect by the EPCs or myeloid cell populations, we analysed the expression of IL- 8 and VEGF by real time PCR, as well as the corresponding concentrations of IL-8 and VEGF in cell cultures supernatants by ELISA(Fig. 5). 

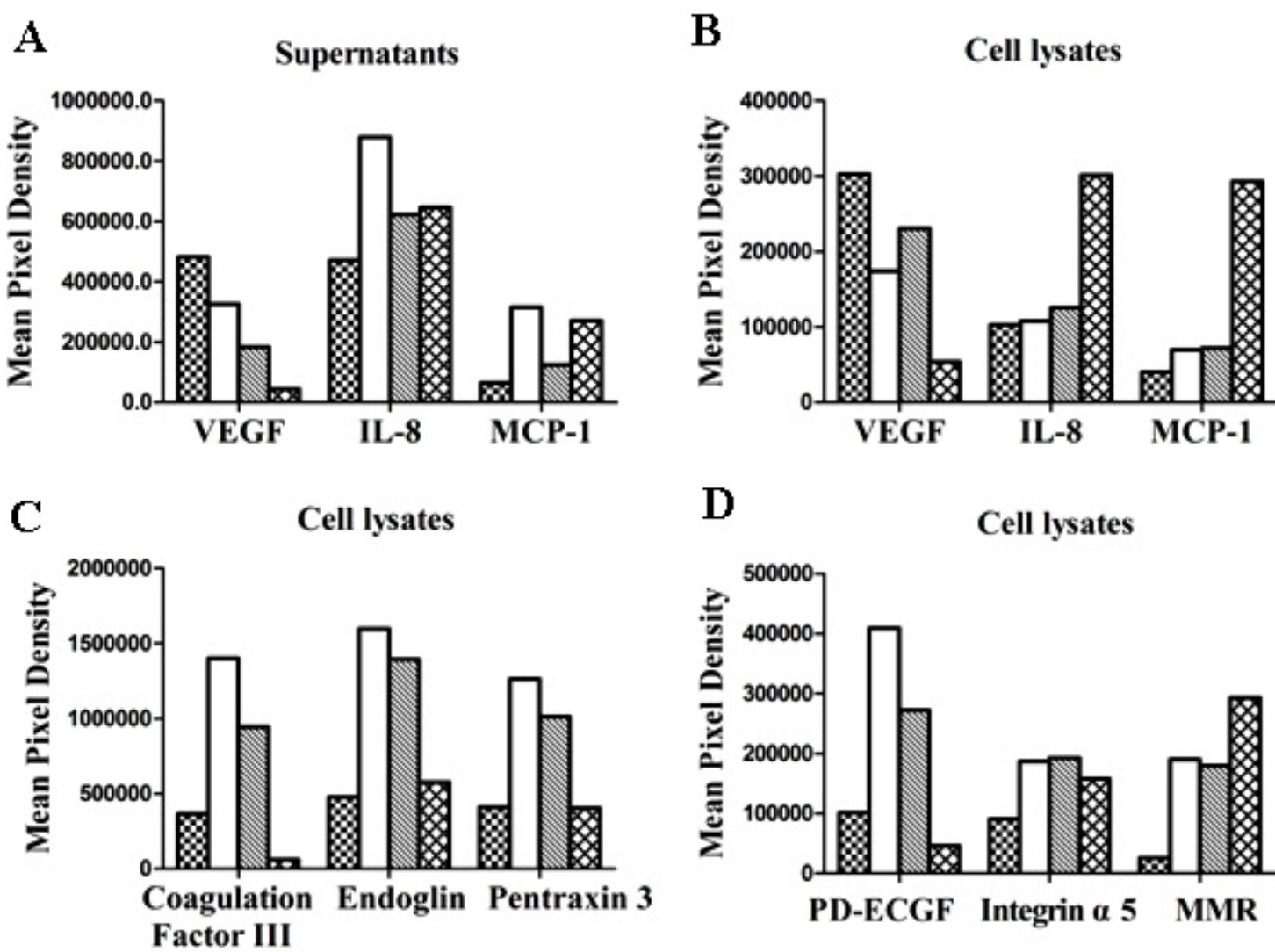

D

Cell lysates

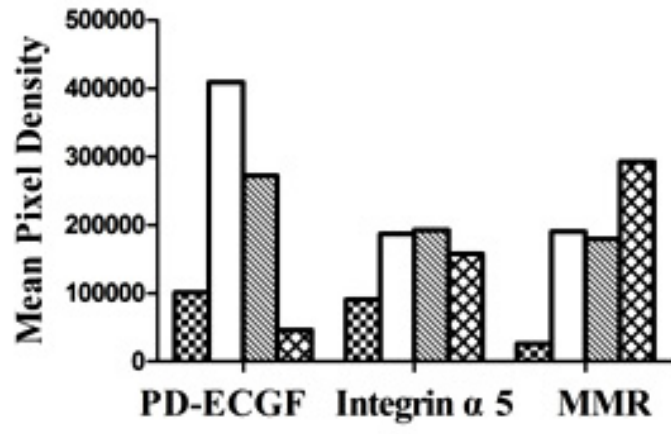

$\infty$ MSC $\square$ MSC+OEC M MSC+OEC+10\%EPC ख OEC

$\mathbf{E}$
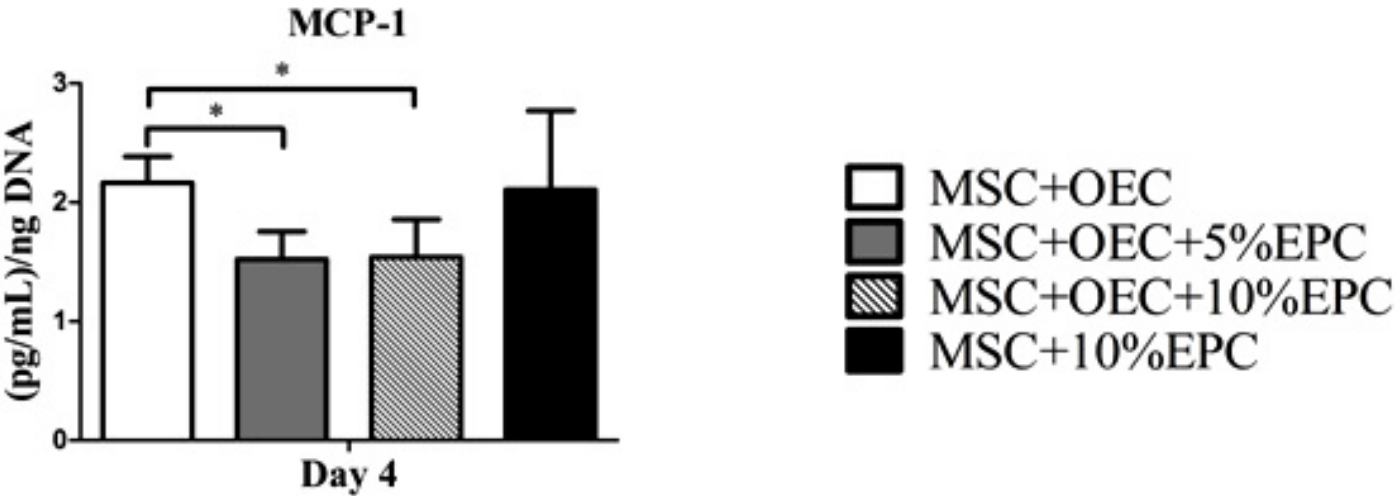

Fig. 6. Human Proteome Profiler Array for Angiogenesis and Haematopoiesis. Quantitative read-out of protein arrays for VEGF, IL-8, MCP-1 in the cell culture supernatants (A) and cell lysates (B) in mono-, co- and triple cultures. Key molecules which drive angiogenesis found in the cell culture lysates $(\mathbf{C}, \mathbf{D})$. Results were depicted as mean pixel densities resulting from protein profiler experiments by pooling the protein extracts in equal ratios from 3 different donors. (E) ELISA for MCP-1 in the cell culture supernatants at day 4 standardised to the DNA content of each sample $(* p<0.05$ and $* * p<0.01, t$-test $), n=3$.

To cope with the different cell numbers in the co-culture set up, VEGF and IL-8 concentrations were normalised to the DNA content. The highest levels of free IL- 8 and VEGF were found in the MSC/ $10 \%$ EPC group (Fig. 5B, $\mathrm{D})$, whereas in the co-cultures where mature endothelial cells were present, the concentration of free IL-8 and
VEGF were lower and showed no differences between the groups at day 4 of the culture. The expression rates of VEGF and IL-8 after 14 days of cultures were slightly higher in the MSC/OEC cultures to which we added the EPC. These results might indicate that EPC or myeloid cells produce IL-8 and trigger the release of VEGF that 
is usually found in high concentrations in osteogenic cell culture supernatants in accordance with our previous reports (Dohle et al., 2010;Kolbe et al., 2011).

\section{Protein arrays for angiogenesis- and haematopoiesis- related proteins}

To assess the production of factors guiding angiogenesis in individual cell types and the effects of the co-cultures on these molecules, we performed protein arrays for angiogenesis- and haematopoiesis-related factors. Protein extracts were harvested from cell culture supernatants and cell lysates to analyse soluble and membrane- or matrixbound fractions of the proteins. For this purpose, proteins from the different fractions and culture approaches were pooled in equal ratios from three independent experiments and thus are depicted as mean values not allowing a statistical approval at this stage but indicating the tentative trend for the individual molecules in the investigated groups. In Fig. 6A and Fig. 6B results are depicted for VEGF, IL-8 and MCP-1 in cell culture supernatants (A) and cell lysates (B). Amongst the groups we assessed, MSC as monocultures are suggested as the main producer of VEGF. In the co-cultures the levels of free VEGF seem to be reduced in comparison to MSC monocultures. Moreover, the addition of EPC to the co-cultures of MSC and OEC further reduced the levels of free VEGF, whereas the cellbound fraction of VEGF in the triple culture of MSC, OEC and EPC, was slightly higher. The highest IL- 8 values in the supernatant were found in those of the co-cultures of OEC and MSC, whereas the highest levels for IL-8 in the cell lysates were found in OEC monocultures. In addition, in OEC lysates MCP-1 (monocyte-chemoattractant protein-1) was enriched, thus favouring the idea that they are the main producer of MCP-1 within the investigated cell types. In comparison, analysis of MCP-1 in the lysates suggested that the addition of EPC or myeloid cells reduces the levels of free MCP-1. Thus, ELISA for MCP-1 were performed for 3 individual donors comparing the amount of MCP-1 found in the cell culture supernatant of the individual coculture groups a (Fig. 6E). These experiments confirmed that the addition of EPC to co-cultures of OEC and MSC lowered the amount of free MCP-1 significantly.

By the protein arrays from cell lysates (Fig. 6 C,D) we identified several molecules which were tentatively upregulated in co- and triple-cultures containing angiogenic structures, compared to MSC or OEC monocultures, in which no angiogenic structures were observed. These molecules include coagulation factor III (also known as tissue factor), endoglin, pentraxin 3, PD-ECGF and integrin- $\alpha$ 5. Furthermore, protein lysates of OEC showed high levels of macrophage mannose receptor (MMR) also known as CD206.

\section{Discussion}

The interaction of resident endothelial cells, bone-forming cells and circulating endothelial progenitor cells is crucial for bone tissue repair and the formation of new and functional microvessels (Melero-Martin et al., 2010). In this context, the present study shows that endogenous myeloid cells in co-cultures of OEC with osteogenic cells are co-localised with angiogenic structures, thus implicating an important role during vascularisation. Those myeloid cells seem to derive from EPC. Flow cytometry and real time PCR have shown that EPC act as myeloid cells and include fractions of cells that carry the endothelial marker CD31 but also express myeloid markers such as CD68, CD206, and CD11b. Those cells with myeloid characteristics mainly reside in the larger cells as indicated by flow cytometry. Consequently, early endothelial progenitor cells added to the co-cultures of MSC and bloodderived endothelial cells (OEC) significantly improved the formation of prevascular structures. The addition of EPC supports the angiogenic process in different ways. This includes a beneficial effect on endothelial cell growth, as indicated by a significant increase in endothelial markers in real time PCR. In addition, EPC or myeloid cells produce angiogenic factors such as IL-8. The recruitment of myeloid cells seems to be mediated by MCP-1 expressed by OEC. Further results indicate that these myeloid cells act as M2 macrophages in co-cultures with MSC and OEC. Thus, the addition of myeloid cells or EPC to complex tissue constructs might help to support the tissue repair and neovascularisation in the bone mediated by their macrophage-like properties.

In previous studies we have shown that outgrowth endothelial cells from the peripheral blood can support the formation of vascular structures in vitro and in vivo (Fuchs et al., 2009a; Kolbe et al., 2011) and might support or accelerate blood perfusion during bone repair and in bone tissue engineered constructs. Nevertheless, it has also been shown that myeloid cells from the host, which are recruited to the sites of tissue repair or to implanted tissue constructs, are also essential for the neovascularisation process (Melero-Martin et al., 2010). This is in accordance with a series of reports identifying myeloid cells as important mediators of neovascularisation (De Palma et al., 2007; Laurent et al., 2011; Van der Pouw Kraan et al., 2012). In co-cultures of OEC with osteogenic cells, staining for the myeloid marker CD11b also indicated a significant colocalisation of myeloid cells with angiogenic structures. Myeloid cells were characterised by their rounded morphology and also partially exhibited the expression of endothelial markers such as CD31. These characteristics are also attributes of endothelial progenitor cells. Myeloid cells are tentatively found at the tips or the nodes of the angiogenic network, which is in accordance with previous reports in the literature about the role of myeloid cells or macrophages-like cells in angiogenesis (Bourghardt Peebo et al., 2011; Fantin et al., 2010; Schmidt and Carmeliet, 2010). These findings prompted us to investigate the role of myeloid cells in the vascularisation process and to refine their role in the context of bone vascularisation. In addition, we wanted to identify the origin of myeloid cells in our co-culture system and to see whether we can use EPC as a pro-angiogenic myeloid cell source.

Analysis of myeloid markers by flow cytometry and real time PCR identified EPC as the major source of myeloid cells in our set up. In this context, the active addition of EPC or myeloid cells, respectively, improved the formation of vascular structures significantly. In order to specify the 
effects of myeloid cells in the cultures we compared the expression of endothelial markers such as vWF, CD31 and CD146, as well smooth muscle actin as an indicator for vessel stabilisation by smooth muscle cells and integrin- $\alpha 5$ for angiogenic activation in quantitative real time PCR. The increase in these markers in the groups to which we have added EPC was consistent through the evaluated endothelial markers and was statistically significant at day 4. In the group of MSC with $10 \%$ EPC the expression of endothelial markers was much lower in accordance with no obvious presence of mature endothelial cells at the investigated time point.

The mechanisms by which the EPC exert beneficial effects on endothelial cell growth could be multifactorial and might include the transdifferentiation of subpopulations of EPC into mature endothelial cells (Bellik et al., 2008). Transdifferentiation of EPC to OEC might also occur in our experimental settings, but could not be proven at the present state. On the other hand, beneficial effects of EPC or myeloid cells on mature endothelial cells might be mediated by paracrine effects.

Some groups have suggested VEGF as a factor that is responsible for the proangiogenic effects of EPC or myeloid cells (Rehman et al., 2003). In addition, VEGF has been reported to recruit CD11b/Gr-1 and CXCR4 neutrophils supporting angiogenesis in mouse models (Christoffersson et al., 2012). In accordance with our previous results and many reports from the literature, MSC were confirmed as the main producer of VEGF in the present study (Wang et al., 2010; Kolbe et al., 2011). By comparing ELISA data, as well as VEGF levels by protein arrays, lower VEGF levels in supernatants and higher levels in cell lysates, reflecting the membrane- or matrix-bound fraction, characterised the triple culture of OEC, MSC and EPC. This is in accordance with previous results investigating the ratios of VEGF in co-culture approaches. These previous studies also indicated low levels of VEGF in the supernatant but higher fractions of membrane- or cell-bound levels of VEGF in cultures with high angiogenic activity (Dohle et al., 2010; Dohle et al., 2011). ELISA data and data from the protein array gave slightly different results but might be associated with differences in the protein harvesting procedure for the arrays or with the normalisation of ELISA data to the cell number.

Another factor that has been proposed to mediate positive effects of myeloid cells on angiogenesis is IL-8 (Medina et al., 2011), triggering endothelial proliferation and angiogenesis (Heidemann et al., 2003; Li et al., 2003). In our studies, IL-8 appears to be derived from the early EPC or from mature endothelial cells. Angiogenic activation in the co-culture of OEC and MSC leads to high levels of IL- 8 in the supernatant, which, in turn, are lowered by the addition of EPC to the system and a further improvement of angiogenesis. We therefore assume that this is associated with the role of IL-8 to recruit myeloid cells or endothelial progenitor cells to sites of vascular reorganisation. In addition, another molecule involved in the recruitment is MCP-1 produced by the OEC, which show the highest rates of MCP-1 in the cell lysates. The addition of EPC leads to lower amounts of MCP-1 in the supernatants compared to the co-culture of $\mathrm{OEC}$ and
MSC. This seems to be in accordance with a monocyte- or macrophage-like phenotype of EPC and the role MCP-1 produced by late outgrowth endothelial cells (Zhang et al., 2009) as an important regulator of angiogenesis. MCP is closely associated with N-Cadherin (Nalla et al., 2011) and induced by angiopoietin-1, leading to the recruitment of mural cells and the stabilisation of angiogenic structures (Aplin et al., 2010). Therefore, the addition of EPC and the resulting lower MCP-1 values could favour a proangiogenic state of the endothelial cells.

In addition, we observed tentative effects on several molecules involved in vascular control by protein arrays. Some of these molecules were much more abundant in cell lysates of co-cultures in which angiogenic structures were present than in the corresponding monocultures which are free of angiogenic structures. Moreover, these molecules seem to be affected by the addition of early EPC or myeloid cells. These factors include coagulation factor III also known as tissue factor, endoglin, pentraxin 3, PD-ECGF and integrin- $\alpha$ 5. The latest was also investigated in real time as described before. Tissue factor is also involved in the formation of complex and stable microvessels characterised by the stabilisation of vascular structures through mesenchymal cells (Carmeliet et al., 1996), which is mediated by the regulation of MCP-1 as described before in the literature (Arderiu et al., 2011) and in accordance with our observations for MCP-1, as described above. Pentraxin-3 is a negative regulator of angiogenesis due to its binding to the proangiogenic molecule fibroblast growth factor-2 (Basile et al., 2013), which is an important factor in the cellular cross talk of endothelial cells, pericytes and stromal cells. Endoglin plays a multifaceted role in vascular biology and is expressed in endothelial cells in inflamed tissues. As recently shown, endoglin is involved in leucocyte adhesion and transmigration in the vascular system via the integrin $\alpha 5 \beta 1$ receptor of leukocytes (Basile et al., 2013). Potential effects on these molecules by the addition of EPC will have to be investigated in more detail.

Surprisingly high levels of macrophage mannose receptor (MMR or CD206) were found in the cell lysates of OEC. Although there are also reports from the literature that this marker is associated with endothelial cells (Groger et al., 2000; Martens et al., 2006), MMR is widely accepted as a M2 macrophage marker (AdutlerLieber et al., 2013; Ambarus et al., 2012; Medina et al., 2011). Further experiments are currently underway to evaluate these findings by additional methods. Real time PCR experiments and flow cytometry indicated that EPC contain macrophage-like cells expressing CD11b, CD68 and CD206.

In co-culture with MSC they might differentiate towards cells with characteristics of M2 macrophages, as indicated by the expression of CD163 in the MSC/EPC cultures. Recently, emerging evidence has been provided that M1 macrophages in co-culture with endothelial cells (He et al., 2012) or mesenchymal stem cells (AdutlerLieber et al., 2013; Eggenhofer et al., 2012; Zhang et al., 2010) assume a M2-like phenotype which is responsible for anti-inflammatory and proangiogenic effects in tissue repair. In this context, the role of EPC or myeloid cells in neovascularisation might be explained by their function 
as macrophage-like cells. Nevertheless, EPC as well as myeloid cells are heterogeneous populations differing in cell size and their marker profile. Therefore, the selection for a specific marker would facilitate their characterisation in terms of therapeutical application later on. On the other hand the crosstalk of different populations is a physiological process also known to influence the behaviour of CD34 positive endothelial progenitor cells, for instance by CD11b positive myeloid cells (Lee et al., 2013). Initial studies were performed to enrich $\mathrm{CD} 11 \mathrm{~b}$ positive myeloid cells from the EPC (data not shown), resulting in cell populations that still revealed a large heterogeneity. Thus, other selection methods have to be considered in the future considering a more complex marker profile.

In summary, the present study gives an insight into the pro-angiogenic action of myeloid cells or endothelial progenitor cells and their molecular action in the bone vascularisation niche made up by endothelial cells, bone forming cells and myeloid or endothelial progenitor cells, respectively. Furthermore, our data provide evidence that mixed application of mature endothelial cells, MSCs and endothelial progenitor cells can support the prevascularisation process.

\section{Acknowledgements}

The authors want to thank Katrin Lange, Gabriele Nessenius, and Barbara Pavic for excellent technical support.

\section{References}

Adutler-Lieber S, Ben-Mordechai T, Naftali-Shani N, Asher E, Loberman D, Raanani E, Leor J (2013) Human macrophage regulation via interaction with cardiac adipose tissue-derived mesenchymal stromal cells. J Cardiovasc Pharmacol Ther 18: 78-86.

Ambarus CA, Krausz S, van Eijk M, Hamann J, Radstake TR, Reedquist KA, Tak PP, Baeten DL (2012) Systematic validation of specific phenotypic markers for in vitro polarized human macrophages. J Immunol Methods 375: 196-206.

Aplin AC, Fogel E, Nicosia RF (2010) Mcp-1 promotes mural cell recruitment during angiogenesis in the aortic ring model. Angiogenesis 13: 219-226.

Arderiu G, Pena E, Aledo R, Juan-Babot O, Badimon L (2011) Tissue factor regulates microvessel formation and stabilization by induction of chemokine (c-c motif) ligand 2 expression. Arterioscler Thromb Vasc Biol 31: 2607-2615.

Asahara T, Masuda H, Takahashi T, Kalka C, Pastore C, Silver M, Kearne M, Magner M, Isner JM (1999) Bone marrow origin of endothelial progenitor cells responsible for postnatal vasculogenesis in physiological and pathological neovascularization. Circ Res 85: 221-228.

Au P, Tam J, Fukumura D, Jain RK (2008) Bone marrow derived mesenchymal stem cells facilitate engineering of long-lasting functional vasculature. Blood 111: 4551-458.
Basile A, Moschetta M, Ditonno P, Ria R, Marech I, De Luisi A, Berardi S, Frassanito MA, Angelucci E, Derudas D, Specchia G, Curci P, Pavone V, Rossini B, Ribatti D, Bottazzi B, Mantovani A, Presta M, Dammacco F, Vacca A (2013) Pentraxin 3 (ptx3) inhibits plasma cell/stromal cell cross-talk in the bone marrow of multiple myeloma patients. J Pathol 229: 87-98.

Bellik L, Musilli C, Vinci MC, Ledda F, Parenti A (2008) Human mature endothelial cells modulate peripheral blood mononuclear cell differentiation toward an endothelial phenotype. Exp Cell Res 314: 2965-2974.

Bourghardt Peebo B, Fagerholm P, Traneus-Rockert C, Lagali N (2011) Time-lapse in vivo imaging of corneal angiogenesis: The role of inflammatory cells in capillary sprouting. Invest Ophthalmol Vis Sci 52: 3060-3068.

Carmeliet P, Mackman N, Moons L, Luther T, Gressens P, Van Vlaenderen L, Demunck H, Kasper M, Breier G, Evrard P, Muller M, Risau W, Edgington T, Collen D (1996) Role of tissue factor in embryonic blood vessel development. Nature 383: 73-75.

Christoffersson G, Vågesjö E, Vandooren J, Lidén M, Massena S, Reinert RB, Brissova M, Powers AC, Opdenakker G, Phillipson M (2012) Vegf-a recruits a proangiogenic mmp-9-delivering neutrophil subset that induces angiogenesis in transplanted hypoxic tissue. Blood 120: 4653-4662.

Covas DT, Panepucci RA, Fontes AM, Silva Jr WA, Orellana MD, Freitas MCC, Neder L, Santos ARD, Peres LC, Jamur MC, Zago MA (2008) Multipotent mesenchymal stromal cells obtained from diverse human tissues share functional properties and gene-expression profile with cd146+ perivascular cells and fibroblasts. Exp Hematol 36: 642-654.

De Palma M, Murdoch C, Venneri MA, Naldini L, Lewis CE (2007) Tie2-expressing monocytes: Regulation of tumor angiogenesis and therapeutic implications. Trends Immunol 28: 519-524.

Dohle E, Fuchs S, Kolbe M, Hofmann A, Schmidt H, Kirkpatrick CJ (2010) Sonic hedgehog promotes angiogenesis and osteogenesis in a coculture system consisting of primary osteoblasts and outgrowth endothelial cells. Tissue Eng Part A 16: 1235-1237.

Dohle E, Fuchs S, Kolbe M, Hofmann A, Schmidt H, Kirkpatrick CJ (2011) Comparative study assessing effects of sonic hedgehog and vegf in a human co-culture model for bone vascularisation strategies. Eur Cell Mater 21: 144-156.

Eggenhofer E, Hoogduijn MJ (2012) Mesenchymal stem cell-educated macrophages. Transplant Res 1: 12.

Fantin A, Vieira JM, Gestri G, Denti L, Schwarz Q, Prykhozhij S, Peri F, Wilson SW, Ruhrberg C (2010) Tissue macrophages act as cellular chaperones for vascular anastomosis downstream of vegf-mediated endothelial tip cell induction. Blood 116: 829-840.

Feng J, Mantesso A, De Bari C, Nishiyama A, Sharpe PT (2011) Dual origin of mesenchymal stem cells contributing to organ growth and repair. Proc Natl Acad Sci USA 108: 6503-6508.

Fuchs S, Hermanns MI, Kirkpatrick CJ (2006a) Retention of a differentiated endothelial phenotype by 
outgrowth endothelial cells isolated from human peripheral blood and expanded in long-term cultures. Cell Tissue Res 326: 79-92.

Fuchs S, Motta A, Migliaresi C, Kirkpatrick CJ (2006b) Outgrowth endothelial cells isolated and expanded from human peripheral blood progenitor cells as a potential source of autologous cells for endothelialization of silk fibroin biomaterials. Biomaterials 27: 5399-5408.

Fuchs S, Hofmann A, Kirkpatrick CJ (2007) Microvessel-like structures from outgrowth endothelial cells from human peripheral blood in 2-dimensional and 3-dimensional co-cultures with osteoblastic lineage cells. Tissue Eng 13: 2577-2588.

Fuchs S, Ghanaati S, Orth C, Barbeck M, Kolbe M, Hofmann A, Eblenkamp M, Gomes M, Reis RL, Kirkpatrick CJ (2009a) Contribution of outgrowth endothelial cells from human peripheral blood on in vivo vascularization of bone tissue engineered constructs based on starch polycaprolactone scaffolds. Biomaterials 30: 526-534.

Fuchs S, Jiang X, Schmidt H, Dohle E, Ghanaati S, Orth C, Hofmann A, Motta A, Migliaresi C, Kirkpatrick CJ (2009b) Dynamic processes involved in the prevascularization of silk fibroin constructs for bone regeneration using outgrowth endothelial cells. Biomaterials 30: 1329-1338.

Fuchs S, Dohle E, Kolbe M, Kirkpatrick CJ (2010) Outgrowth endothelial cells: Sources, characteristics and potential applications in tissue engineering and regenerative medicine. Adv Biochem Eng Biotechnol 123: 201-217.

Ghanaati S, Fuchs S, Webber MJ, Orth C, Barbeck M, Gomes ME, Reis RL, Kirkpatrick CJ (2011) Rapid vascularization of starch-poly(caprolactone) in vivo by outgrowth endothelial cells in co-culture with primary osteoblasts. J Tissue Eng Regen Med 5: e136-143.

Groger M, Holnthoner W, Maurer D, Lechleitner S, Wolff K, Mayr BB, Lubitz W, Petzelbauer P (2000) Dermal microvascular endothelial cells express the 180kda macrophage mannose receptor in situ and in vitro. J Immunol 165: 5428-5434.

Gulati R, Jevremovic D, Peterson TE, Chatterjee S, Shah V, Vile RG, Simari RD (2003) Diverse origin and function of cells with endothelial phenotype obtained from adult human blood. Circ Res 93: 1023-1025.

He H, Xu J, Warren CM, Duan D, Li X, Wu L, IruelaArispe ML (2012) Endothelial cells provide an instructive niche for the differentiation and functional polarization of m2-like macrophages. Blood 120: 3152-3162.

Heidemann J, Ogawa H, Dwinell MB, Rafiee P, Maaser C, Gockel HR, Otterson MF, Ota DM, Lugering N, Domschke W, Binion DG (2003) Angiogenic effects of interleukin $8(\operatorname{cxcl} 8)$ in human intestinal microvascular endothelial cells are mediated by cxcr2. J Biol Chem 278: 8508-8515.

Hur J, Yoon CH, Kim HS, Choi JH, Kang HJ, Hwang KK, Oh BH, Lee MM, Park YB (2004) Characterization of two types of endothelial progenitor cells and their different contributions to neovasculogenesis. Arterioscler Thromb Vasc Biol 24: 288-293.
Kolbe M, Xiang Z, Dohle E, Tonak M, Kirkpatrick CJ, Fuchs S (2011) Paracrine effects influenced by cell culture medium and consequences on microvessel-like structures in cocultures of mesenchymal stem cells and outgrowth endothelial cells. Tissue Eng Part A 17: 2199-2212.

Laschke MW, Menger MD (2012) Vascularization in tissue engineering: Angiogenesis versus inosculation. Eur Surg Res 48: 85-92.

Laurent J, Touvrey C, Botta F, Kuonen F, Ruegg C (2011) Emerging paradigms and questions on proangiogenic bone marrow-derived myelomonocytic cells. Int J Dev Biol 55: 527-534.

Lee JH, Lee SH, Yoo SY, Asahara T, Kwon SM (2013) $\mathrm{Cd} 34$ hybrid cells promote endothelial colony-forming cell bioactivity and therapeutic potential for ischemic diseases. Arterioscler Thromb Vasc Biol 33: 1622-1634.

Li A, Dubey S, Varney ML, Dave BJ, Singh RK (2003) Il-8 directly enhanced endothelial cell survival, proliferation, and matrix metalloproteinases production and regulated angiogenesis. J Immunol 170: 3369-3376.

Liu Y, Teoh S-H, Chong MSK, Lee ESM, Mattar CNZ, Randhawa NsK, Zhang Z-Y, Medina RJ, Kamm RD, Fisk NM, Choolani M, Chan JKY (2012) Vasculogenic and osteogenesis-enhancing potential of human umbilical cord blood endothelial colony-forming cells. Stem Cells 30: 1911-1924.

Martens JH, Kzhyshkowska J, Falkowski-Hansen M, Schledzewski K, Gratchev A, Mansmann U, Schmuttermaier C, Dippel E, Koenen W, Riedel F, Sankala M, Tryggvason K, Kobzik L, Moldenhauer G, Arnold B, Goerdt S (2006) Differential expression of a gene signature for scavenger/ lectin receptors by endothelial cells and macrophages in human lymph node sinuses, the primary sites of regional metastasis. J Pathol 208: 574-589.

Medina RJ, O’Neill CL, O’Doherty TM, Knott H, Guduric-Fuchs J, Gardiner TA, Stitt AW (2011) Myeloid angiogenic cells act as alternative $\mathrm{m} 2$ macrophages and modulate angiogenesis through interleukin-8. Mol Med 17: 1045-1055.

Melero-Martin JM, Khan ZA, Picard A, Wu X, Paruchuri S, Bischoff J (2007) In vivo vasculogenic potential of human blood-derived endothelial progenitor cells. Blood 109: 4761-4768.

Melero-Martin JM, De Obaldia ME, Allen P, Dudley AC, Klagsbrun M, Bischoff J (2010) Host myeloid cells are necessary for creating bioengineered human vascular networks in vivo. Tissue Eng Part A 16: 2457-2466.

Nalla AK, Estes N, Patel J, Rao JS (2011) N-cadherin mediates angiogenesis by regulating monocyte chemoattractant protein-1 expression via pi3k/akt signaling in prostate cancer cells. Exp Cell Res 317: 2512-2521.

Okuno Y, Nakamura-Ishizu A, Kishi K, Suda T, Kubota Y (2011) Bone marrow-derived cells serve as proangiogenic macrophages but not endothelial cells in wound healing. Blood 117: 5264-5272.

Rasband WS (1997-2012), http://imagej.nih.gov/ij/.

Rehman J, Li J, Orschell CM, March KL (2003) Peripheral blood "endothelial progenitor cells" are derived from monocyte/macrophages and secrete angiogenic growth factors. Circulation 107: 1164-1169. 
Rivron NC, Raiss CC, Liu J, Nandakumar A, Sticht C, Gretz N, Truckenmüller R, Rouwkema J, van Blitterswijk CA (2012) Sonic hedgehog-activated engineered blood vessels enhance bone tissue formation. Proc Natl Acad Sci USA 109: 4413-4418.

Rouwkema J, Rivron NC, van Blitterswijk CA (2008) Vascularization in tissue engineering. Trends Biotechnol 26: 434-441.

Scherberich A, Galli R, Jaquiery C, Farhadi J, Martin I (2007) Three-dimensional perfusion culture of human adipose tissue-derived endothelial and osteoblastic progenitors generates osteogenic constructs with intrinsic vascularization capacity. Stem Cells 25: 1823-1829.

Schmidt T, Carmeliet P (2010) Blood-vessel formation: Bridges that guide and unite. Nature 465: 697-699.

Schmidt H, Kramer G, Shi Y, Kirkpatrick CJ, Fuchs S (2012) Object-based colocalization of angiogenic structures and myeloid cells. In: Proc ImageJ User and Developer Conf, Luxembourg, pp 192.

Timmermans F, Plum J, Yöder MC, Ingram DA, Vandekerckhove B, Case J (2009) Endothelial progenitor cells: Identity defined? J Cell Mol Med 13: 87-102.

Van der Pouw Kraan TC, van der Laan AM, Piek JJ, Horrevoets AJ (2012) Surfing the data tsunami, a bioinformatic dissection of the proangiogenic monocyte. Vascul Pharmacol 56: 297-305.

Wang L, Fan H, Zhang ZY, Lou AJ, Pei GX, Jiang S, Mu TW, Qin JJ, Chen SY, Jin D (2010) Osteogenesis and angiogenesis of tissue-engineered bone constructed by prevascularized beta-tricalcium phosphate scaffold and mesenchymal stem cells. Biomaterials 31: 9452-9461.

Yoder MC, Mead LE, Prater D, Krier TR, Mroueh KN, Li F, Krasich R, Temm CJ, Prchal JT, Ingram DA (2007) Redefining endothelial progenitor cells via clonal analysis and hematopoietic stem/progenitor cell principals. Blood 109: 1801-1809.

Yoon CH, Hur J, Park KW, Kim JH, Lee CS, Oh IY, Kim TY, Cho HJ, Kang HJ, Chae IH, Yang HK, Oh BH, Park YB, Kim HS (2005) Synergistic neovascularization by mixed transplantation of early endothelial progenitor cells and late outgrowth endothelial cells: The role of angiogenic cytokines and matrix metalloproteinases. Circulation 112: 1618-1627.

Zhang QZ, Su WR, Shi SH, Wilder-Smith P, Xiang AP, Wong A, Nguyen AL, Kwon CW, Le AD (2010) Human gingiva-derived mesenchymal stem cells elicit polarization of $\mathrm{m} 2$ macrophages and enhance cutaneous wound healing. Stem Cells 28: 1856-1868.

Zhang Y, Ingram DA, Murphy MP, Saadatzadeh MR, Mead LE, Prater DN, Rehman J (2009) Release of proinflammatory mediators and expression of proinflammatory adhesion molecules by endothelial progenitor cells. Am J Physiol Heart Circ Physiol 296: H1675-H1682.

\section{Discussion with Reviewers}

M. Herrman: Which part of the EPCs does actually have an effect on the visualisation process? Is the increase of endothelial marker and increased formation of vascular structures mediated by differentiating EPCs or by myeloid cells (requires either sorting/enrichment of distinct population and/or tracking experiments and/or controls using pure myeloid cells)?

Authors: In terms of the question which subpopulation of the EPC is driving the angiogenesis forward, we fully agree that it is a very important scientific question to differentiate between paracrine and transdifferentiation effects by EPC. Nevertheless, the impact of these cells on the angiogenesis of the co-culture model just became clear during the time course of this present study. Of course, we would like to solve this issue but we would like to point out again the clear line of evidence provided by our results that the majority of EPC act as accessory or helper cells and that this might be explained by their function as proangiogenic macrophage/myeloid like cells. Nevertheless, we cannot exclude a transdifferentiation process by some EPC subpopulations as stated already in the text, but this mechanism might contribute to the proangiogenic effect of EPC/myeloid cells in our system to a much lower extent.

If the proangiogenic process would be mainly based on a transdifferentiation process of EPC or myeloid cells, one would expect that we would have to add a higher ratio of EPC to observe such an effect. In comparison, OEC which have grown out from EPC cultures are observed in low frequencies in these cultures (reference values $0.05-0.2$ an $\mathrm{OEC} / \mathrm{mL}$ blood; or represent only $0.01 \%$ to $0.0001 \%$ of MNC, compare also Kolbe et al., 2010, text reference) also reflected by the low expression of endothelial markers in EPC in real time PCR. Nevertheless, the impact of these EPC or the myeloid cells on angiogenesis increases drastically when mature cell are present which are resembled by the OEC in our system.

Interestingly, a recent paper investigated effects of CD11b positive cells on CD34 positive cells from the peripheral blood in an indirect co-culture system. In this study CD11b positive cells stimulated the colony formation of CD34 positive cells indicating a supporting role of myeloid cells on CD34 positive EPC or OEC by paracrine mechanisms (Lee et al., 2013, additional reference). Our data seem to be in accordance with the observations of this recently published paper although this study did not use EPC cultures for the isolation of CD11b positive cells.

M. Alini: What is the source of myeloid cells within the EPC population? (The authors did indeed provide a double staining of CD31 and several myeloid marker, but as CD31 is not specific to endothelial cells but also present on myeloid cells (e.g., Woolfin et al., 2007, additional reference) a double staining with a different, more specific endothelial marker would be required.

Authors: We already did flow cytometric evaluation of other surface markers related to a mature endothelial phenotype in EPC as published previously (Fuchs et al., 2006, text reference) indicating that EPC are negative for CD146 for instance. We accordingly added data for flow cytometry for CD146 into the present manuscript (Table 2) to document again that EPC do not express CD146. In addition, we would like to refer again to the real time PCR data for EPC or EPC in Co-culture with MSC where we 
also show the absence of other endothelial markers such as vWF, caveolin-1 etc. in EPC. These results again underline that the EPC do not express the full marker profile of mature endothelial cells but they might contain progenitors or mature endothelial cells in a very low frequency.

M. Alini: Concerning the possible mechanism of myeloid cells the authors added some interesting data on MCP-1 (Fig. 6E). The ELISA data suggests that OEC produce high level of MCP-1, which is reduced by the addition of EPC. Here, it is not clear and not explained where the high levels of MCP-1 in MSC/EPC co-culture derive from.

Authors: ELISA data are normalised to the cell number using the DNA content. This normalisation is responsible for the high appearance of MCP-1 in the supernatants of the MSC/EPC group if we take out the normalisation the levels are close to that of the triple cultures. Our intention is to show that the addition of EPC to co-culture of OEC and MSC significantly reduces the level of free MCP-1 in the supernatant.

\section{Additional References}

Lee JH, Lee SH, Yoo SY, Ashara T, Kwon SM (2013) Hybrid cells promote endothelial colony-forming cell bioactivity and therapeutic potential for ischemic diseases. Arterioscler Thromb Vasc Biol 33:1622-1634.

Woolfin A, Voisin M-B, Nourshargh S (2007) PECAM-1: A multi-functional molecule in inflammation and vascular biology. Arterioscler Thromb Vasc Biol 27: 2514-2523. 